\title{
Indígena y abogado: el caso de José Domingo Choquehuanca de Azángaro*
}

\section{Indigenous lawyer: the case of José Domingo Choquehuanca of Azangaro}

\author{
In memoriam \\ Augusto Ramos Zambrano
}

NURIA SALA I VILA

Universidad de Girona

nuria-sala@udg.edu

Este ensayo tiene como tema el pensamiento politico de José Domingo Choquehuanca, miembro de una familia de nobles indígenas, quienes, desde la colonia y durante el primer siglo republicano, ocuparon cargos administrativos, judiciales y politicos desde su centro de poder regional. De este modo, José Domingo se ubicó en un periodo clave de transición entre el sistema colonial hispano y la formación de una república, siendo él parte del grupo de intelectuales que laboró una base juridica liberal para la naciente nación. Sobre la base del estudio de su vida y publicaciones, se sugiere que Choquehuanca preservó simbolos de su autoridad señorial, pero moldeándose a los constantes cambios de un Perú convulso política y socialmente, lo que marcó el desarrollo de su pensamiento politico en un contexto nuevo de meritocracia e igualdad.

Palabras clave: José Domingo Choquehuanca, liberalismo, estadistica, cultura jurídica, Puno.

Investigación en el marco del proyecto HAR2014-53160.

hISTORIOn XLII.2 (2018): 43-88 / ISSN 0252-8894

https://doi.org/10.18800/historica.201802.002 


\section{ABSTRACT}

This essay focuses on the political thought of Jose Domingo Choquehuanca, a member of a family of indigenous nobles that, from the colonial period and the first Republican century, occupied administrative, judicial, and political posts in their regional power center. Thus, José Domingo found himself in a key transitional period between the Spanish colonial system and the formation of the republic; a member of a group of intellectuals who laid a liberal juridical foundation for the newly-born nation. This study suggests that Choquehuanca preserved symbols of his seigneurial authority while following the constant changes of a politically and socially tumultuous Peru, which informed the development of his political thought in a new context of meritocracy and equality.

Keywords: José Domingo Choquehuanca, liberalism, statistics, juridical culture, Puno.

$\mathrm{L}$ as gentes que vivieron la realidad colonial y del Antiguo Régimen comportamiento social. Actores individuales, linajes, o las múltiples instituciones y corporaciones laicas y eclesiásticas siguieron pautas definidas secularmente y engarzadas en el complejo entramado de una sociedad estamental, que aceptaba y regulaba la diferencia religiosa o étnica. En las décadas finales del siglo XVIII y las tempranas del siglo XIX, muchas cosas cambiaron y el statu quo anterior fue cuestionado, aunque muchas de sus ańejas características tardarían mucho tiempo en desaparecer. Quienes vivieron esos años, -entre dos y tres generaciones-, no tuvieron un plan u hoja de ruta preconcebida, los debates y proyectos políticos fueron múltiples y no todos fluían en un mismo sentido. Hubo quienes querían mantenerse en lo tradicional, porque garantizaba un devenir previsible o les aseguraba la preeminencia socioeconómica, mientras que otros aceptaban nuevas formas y pautas sociales, educativas y/o culturales, lo que llevaría a alguno de ellos, de forma consciente o inconsciente, a asumir el liderazgo político en la nueva era liberal.

En un trabajo reciente, he propuesto cuatro periodos que marcaron la formación del estado liberal en el Perú decimonónico. Bajo el presupuesto 
de que el liberalismo solo pudo construirse cuando los saberes expertos ocuparon espacios de poder estratégico, se habrían sucedido o superpuesto los tiempos de los abogados, de los estadísticos, de los geógrafos y de los ingenieros. ${ }^{1}$ Para estos hombres de ciencia, su meta fue conocer y moldear la realidad jurídica, humana, territorial y revertirla en motor de progreso técnico. Y para formarlos, se afrontó una profunda y radical transformación del sistema educativo.

A fines del período colonial, emergieron nuevos actores sociales — profesionales, intelectuales - y entre ellos, los abogados asumieron nuevas pautas, deviniendo en uno de los grupos más influyentes en su quehacer laboral y en la práctica política. Su formación estuvo influida por el pensamiento jurídico de la Ilustración napolitana y de sus autores más representativos, Cesare Beccaria o Gaetano Filangieri, y por quienes sentaron las bases de la cultura jurídica liberal. ${ }^{2}$ La práctica judicial incidió en su capacidad argumentativa y discursiva, ${ }^{3}$ convirtiéndose en un puntal en la conformación de los poderes judicial y legislativo, y, en buena medida, del gubernativo en las nacientes repúblicas americanas.

En las siguientes páginas, abordaré un esbozo de biografía intelectual y política de José Domingo Choquehuanca (Azángaro, 1792-1854/8?), atendiendo en especial a su formación de abogado y su inserción en las nuevas prácticas políticas que se impusieron en el liberalismo hispano y tras la Independencia hasta promediar la década de 1840 . Nos parece conveniente dedicarle un estudio particular, puesto que fue uno de los pocos miembros de linajes de nobles indígenas que lograron cargos de representación parlamentaria en el siglo XIX peruano. Mi objetivo es reconstruir su formación letrada, su carrera política, junto a su ideario y la imagen que se construyó sobre la política y cultura jurídica de su tiempo. El personaje tuvo la capacidad de trascender en el imaginario de la construcción nacional y fue objeto de atención temprana entre panegiristas, literatos e historiadores. Su ciclo se inició ya en el siglo XIX

1 Sala i Vila 2016a.

2 Gori 2016; Irurozqui 2016.

3 Ricketts 2013 y 2017. 
con la reproducción de la arenga lírica que dedicó a Bolívar (Pucará, 1825) por el jurista Francisco García Calderón; ${ }^{4}$ luego, con el elogio a su obra estadística por el naturalista Antonio Raimondi; ${ }^{5}$ y, después, con el énfasis en su papel de hombre político reclamado desde el indigenismo por Clorinda Matto de Turner. ${ }^{6}$ En el siglo XX, fue objeto de culto entre genealogistas incanistas, ${ }^{7}$ sin que se dejara de lado el interés por su labor política y de escritor; además de ser ensalzado por ser bolivariano ${ }^{8}$ y por sus acciones y textos políticos.

Así, el linaje de los Choquehuanca ha dado lugar a una amplia ensayística e historiografía. Esta familia fue leal a la Corona durante los conflictos enquistados en el sur del virreinato del Perú desde 1780 hasta 1824. Sus miembros diversificaron sus posiciones desde las luchas por la Independencia, hasta el conflicto de la Confederación Peruano-Boliviana (1836-1839); unos defendieron el Absolutismo y otros, el Liberalismo. Desde su tradición señorial, lograrían adecuarse al tránsito hacia gobiernos representativos y acceder a cargos electivos locales, regionales y nacionales, y/o gubernativos, siempre desde su base de poder centrado en Azángaro. Además, modificarían sustancialmente su relación textual con el poder: los memoriales, demandas y alegatos ante corregidores, audiencias, Consejo de Indias o la Corona serían sustituidos por la correspondencia con los caudillos, la edición de folletos o artículos en la prensa regional, donde desplegaron las bases de su propuesta ideológica y política o vindicaron su posición ante prefectos y presidentes en diversas coyunturas políticas. Por último, cabe recordar, que, en sociedades como la peruana, la transición de las sociedades estamentales y patriarcales hacia otras de mérito e igualitarias fue muy lenta y se mantuvieron, tanto en la

4 La arenga lírica de Choquehuanca se incluyó en la voz «Bolívar» del Diccionario de García Calderón (1860-1862, 1: 313). Romero (1936: 41-47) cuestionó su autoría y la atribuyó a su primo Manuel José Choquehuanca.

5 Raimondi 1876-1879: 106.

6 Matto 1890; Ortiz 2007.

7 Cuentas 1925; Mostajo 1953; Puertas 1963; Coloma 1989.

8 Acevedo 1922; Luna 1946; Puertas 1948 y 1953; Frisancho 1953; Ratto-Ciarlo 1980; Altuve 1991.

9 Frisancho 1953 y 1975; Ramos Zambrano 2012. 
esfera privada como en la pública, fuertes lazos familiares, junto a otros de compadrazgo y patronazgo, trascendiendo la conciencia de pertenencia a un grupo privilegiado y con vocación de poder. Una realidad que se sumó a la convicción étnica y de estatus social que vinculaba la riqueza al parentesco y que permitía el acceso a la reciprocidad y al uso de recursos, ${ }^{10}$ por lo que se hace aún más pertinente estudiar las actitudes de un linaje o de alguno de sus miembros en la larga duración, para comprender las múltiples estrategias de inserción en sociedades estamentales o incipientemente liberales.

La base de poder de los Choquehuanca radicó en Azángaro, un pueblo de reducción toledana situado en el altiplano de Puno, que a lo largo de la Colonia y la República fue cabecera sucesivamente del corregimiento, partido y provincia del mismo nombre, bajo jurisdicción de la audiencia de Charcas hasta la creación de la del Cusco en 1784, y sujeto, al igual que toda la región puneña, al virreinato del Rio de la Plata entre 1776 y 1790. Azángaro se organizó en dos parcialidades, gobernadas en el siglo XVIII por dos familias de curacas, los Choquehuanca en anansaya ${ }^{11} \mathrm{y}$ los Mango Turpo en urisanya. Si bien carecía de cabildo pleno, existía una suerte de gobierno local, que estuvo bajo el control de la pequeńa elite blanca del lugar. A principios del siglo XIX, era una zona quechuahablante, que difería lingüísticamente del resto del Puno aimara, quizás por su adscripción al obispado del Cusco, que optó por dicha lengua general para evangelizar a los indios. Un testimonio parcial de 1790 estimaba su población en 100 vecinos, de los cuales unos 80 serían espańoles y el resto «indios y cholada». ${ }^{12}$ Según José Domingo Choquehuanca, en la década de 1820 su población urbana y rústica era respectivamente de 517 blancos y 6.092 indios; 657 tenían, según el registro cívico,

\footnotetext{
${ }^{10}$ Rosas 2009.

${ }^{11}$ Identificaban al grupo dentro de la inicial encomienda de Gómez de Quiñones. Archivo Histórico Nacional [en adelante AHN], Estado, Pruebas de nobleza de la Orden de Carlos III, 710).

${ }^{12}$ Carta de Ignacio Torado al director general Francisco Undarreta, Puno, 13 de agosto de 1792, Archivo General de la Nación, Argentina [en adelante AGNA] Intendencia de Puno, 6.1.7, 1792-93.
} 
categoría de ciudadanos; y en los recuentos fiscales, 293 constaban como originarios y 1021 como sobrinos/forasteros, según fueran o no naturales del lugar y tuvieran o no acceso a las tierras comunales, ${ }^{13}$ o gozaran del derecho a ejercer cargos en el cabildo indígena. ${ }^{14}$

\section{DE CURACAS A ELITES REGIONALES: LOS CHOQUEHUANCA ENTRE COLONIA Y REPÚBLICA}

Diego Choquehuanca fue cacique en Azángaro durante más o menos medio siglo y hasta su muerte en 1796. Según Scarlett O’Phelan, una serie de caciques (entre ellos, Pedro Sahuaraura, Francisco Guambotupa y Diego Choquehuanca) presentaron probanzas de nobleza, elaboraron árboles genealógicos o costearon iglesias y altares para reforzar su prestancia social. El resultado de la confluencia de los intereses de la Corona y las elites indias supuso la concesión, a partir de 1745, de seis títulos de Castilla a curacas, quienes se mantendrían leales a lo largo de la convulsa segunda mitad del siglo XVIII. Fue en esa coyuntura, que Diego Choquehuanca obtuvo en 1766 una Real Provisión de la Real Audiencia de Charcas, que le reconocía el derecho a portar armas y tener blasón. ${ }^{15}$

Al reconocimiento de su nobleza, se uniría su capacidad de acumulación económica. De acuerdo con su testamento, explotó unas 16 propiedades agrícolas y mineras, entre ellas las hacienda-estancias de Picotani, Checayani y Nequeneque en Muñani y Puscallani, Ccalla y Catacora, la mayoría alrededor de Azángaro, aunque al menos tres estaban en las cercanías de la ciudad de Puno. Si en 1760 estimó su ganado en 1.600 vacas, 300 ovejas, 500 cerdos, 300 llamas, 70 cabras, 20 pares de bueyes

\footnotetext{
13 Choquehuanca 1833: 15-16.

${ }^{14}$ Choquehuanca clasificó a los indígenas y al referirse a los originarios refería textualmente «los principales eran los originarios... esentos de ser obligados a los servicios mecánicos y podían obtar a los cargos concejiles de Alcaldes de naturales según la ordenanza de Toledo; y por cierta especie de distinción tenían asiento en el cabildo, en las asistencias de Iglesia» (1833: 67).

${ }^{15}$ Orden de Carlos III, AHN, Estado, 710; O’Phelan 1998: 152-165.
} 
y 2 mulas; a su muerte en 1792 , disponía de unas 14.000 ovejas. ${ }^{16}$ A sus propiedades directas se sumaría, en la década de 1790, la gestión de la hacienda Caravilque de propiedad comunal. ${ }^{17} \mathrm{El}$ caso de Diego Choquehuanca ha sido destacado como uno de los ejemplos del proceso de diferenciación social que se produjo al interior del mundo indígena a lo largo del siglo XVIII, en parte como consecuencia de la participación de los caciques en el entramado extractivo que los corregidores organizaron en torno al reparto forzoso de mercancías. Nils Jacobsen lo atribuye tanto al control de la comunidad, como de los yanaconas de sus estancias. ${ }^{18}$ La disputa por el excedente indígena habría resquebrajado la cohesión de las elites regionales, lo que en parte explicaría el alcance de la rebelión de Tupac Amaru en la zona. Así, cabe recordar que en su fase radical posterior al ajusticiamiento de Tupac Amaru, Azángaro se conventiría en uno de los focos insurgentes del altiplano. El linaje y los bienes de los Choquehuanca fueron blanco de las iras rebeldes: se saquearon y expoliaron 11 de sus 16 propiedades con graves pérdidas de ganado. ${ }^{19}$ Diego y parte de la familia huyeron para salvar sus vidas, primero hacia Arequipa y luego a Charcas. Su hija María del Rosario moriría en el trasiego; entre tanto, su hija Teresa se refugió en el beaterio de Copacabana y su hijo Blas fue ahorcado por los rebeldes en Sorata.

Tras la inicial represión postrebelión, y ante la persistencia de denuncias de los comuneros de Azángaro anansaya contra su cacique ante los tribunales locales de justicia, tanto la Audiencia de Charcas como el Consejo de Indias pudieron ser favorables a los intereses comuneros en su afán por limitar las corruptelas de corregidores, curacas o curas y para lograr el objetivo de la política borbónica de aumentar los ingresos fiscales coloniales y, en parte, para pacificar definitivamente la región. ${ }^{20}$

${ }^{16}$ Garret 2009: 208-209. El testamento ha sido reproducido en Ramos Zambrano 2012: 189-198.

${ }^{17}$ Biblioteca Nacional del Perú [en adelante BNP], Mss. C 737.

${ }^{18}$ Jacobsen 2013: 146-147.

${ }^{19}$ Piel 1972, v. 1: 201; Jacobsen 2013: 92-94.

${ }^{20}$ Jacobsen 2013: 165-169. 
Diego Choquehuanca proyectó en su prole - Roque, Gregorio, José, Blas, María del Rosario, Teresa y Dominica - una estrategia diversificada: José y Blas fueron oficiales de milicias étnicas; Gregorio se ordenó sacerdote y ocupó puestos en el cabildo de la catedral de Chuquisaca, y por sus méritos personales y familiares fue agraciado con la orden de Carlos III; ${ }^{21}$ su hija Dominica fue monja en el convento de clausura de Santa Catalina de Arequipa; María Teresa heredó el gobierno señorial, ante la temprana muerte de sus hermanos varones, ${ }^{22}$ compartiendo su gestión y recaudación fiscal con su marido el criollo sargento mayor Nicolás de la Cámara. El matrimonio de María Teresa confirmaría la hipótesis de David Garret del abandono por parte de la nobleza indígena de cierta tradición de favorecer el matrimonio de sus vástagos con otros de igual o menor rango estamental y étnico, en pos de nuevas alianzas con españoles/criollos o con estratos de la alta nobleza étnica, empeño para el que destinaron importantes recursos por medio de las dotes, que supusieron transferencias sustanciales de la economía indígena a la criolla, con el objetivo de tentar nuevas formas de inserción en los altos estratos sociopolíticos —educación, eclesiásticas, profesionalización, cargos gubernativos y representativos -.${ }^{23}$ Con todo, hubo de afrontar la oposición de los comuneros y los varones de la familia, un conflicto que fue resuelto por las autoridades políticas y judiciales reconociendo al hijo de Blas, Manuel José, su derecho preferente al cargo de curaca por ser el único varón de la familia mayor de edad. ${ }^{24}$

Diego y Manuel José Choquehuanca defendieron el orden colonial de raíz absolutista. El primero, en la Gran Rebelión (1780-83) y el segundo, durante la larga coyuntura insurgente abierta en 1808 por la

\footnotetext{
${ }^{21}$ Expediente 710, AHN, Estado, Carlos III, 1793.

${ }^{22}$ Referencias de ocupar el cargo entre 1792 y 1797, BNP, Mss. C 737 y AGN. 6.2.3. Intendencia de Puno, 1757-1807.

23 Garret 2009: 175-177 y 221-222.

${ }^{24}$ Garrett 2008. El intendente de Puno le nombró cacique interino el 10 de setiembre de 1798; la Audiencia del Cusco le otorgó el título definitivo por auto de 13.8.1810. Archivo Regional del Cusco [en adelante ARC], Real Audiencia, Asuntos Administrativos, leg. 169.
} 
vacancia regia de Fernando VII. En el periodo comprendido entre el establecimiento de la Junta Tuitiva de La Paz en 1809 y fines de 1816, las regiones situadas en torno al eje que une imaginariamente Cusco, el lago Titicaca y Potosí vieron sucederse múltiples proyectos y entrar en conflicto diversos actores políticos, fueran absolutistas, juntistas, liberales o defendieran propuesta netamente étnicas. La Junta Tuitiva de La Paz pondría en la agenda política nuevos actores y viejas concepciones, reclamando la reversión de la soberanía al pueblo ante el exilio forzado del rey. ${ }^{25}$ Las campañas rioplatenses por el control de Charcas fracasaron una tras otra, pero la dirigida por el jacobino Juan José Castelli quedaría en la memoria de muchos, y el eco de su prédica de abolición del tributo en Tiahuanaco llegaría hasta la sierra central del Perú, identificándosele como el inca que traía la igualdad. ${ }^{26}$ Entre 1810 y 1811 , el altiplano paceño y puneño fue escenario de una rebelión indígena y para combatirla y restituir el orden y la autoridad hispana, el ejército realista se reforzaría con tropas indias provenientes del Cusco y Azángaro, comandadas respectivamente por Mateo Pumacahua y Manuel José Choquehuanca. ${ }^{27}$ Este último coordinó las levas indígenas en el altiplano puneño y actuó en las campañas contrainsurgentes represoras, efectuadas en las riberas del Titicaca y la región de La Paz en 1811 contra los indios sublevados en Guaqui, Tihuanaco, Tiquina y Huancané. ${ }^{28}$

El Primer Liberalismo Hispano (1810-14) comportó cambios sustanciales para los indios de Azángaro: abolición de los servicios personales, del tributo y la mita; separación de poderes (si bien el alcalde seguía siendo considerado juez lego para causas menores y de conciliación); ${ }^{29}$ fin de los gobiernos étnicos a raíz de la constitución de ayuntamientos electivos multiétnicos; elecciones a ayuntamientos, diputaciones provinciales y cortes generales. Algo hemos indagado sobre dos factores

\footnotetext{
${ }^{25}$ Irurozqui 2007.

${ }^{26}$ Sala i Vila 1990; Wasserman 2011.

27 Soux 2011: 455-482.

${ }^{28}$ Oficios de Manuel Químper, intendente de Puno, al virrey Abascal, 7 de enero de 1812 y 18 de junio de1813, BNP, Mss. D 457, No 258.

${ }^{29}$ Sala i Vila, 2012.
} 
que modificaron sustancialmente la vida cotidiana pueblerina a raíz del accionar de alcaldes y cargos concejiles electos, y de la suspensión por el virrey Fernando de Abascal de la igualdad fiscal para sostener el costo de la represión en los Andes. En general, los cargos de curacas y alcaldes indios perdieron legalmente su capacidad de intermediación. ${ }^{30}$ En 1813, el Ayuntamiento Constitucional de Azángaro se hallaba integrado, según sus propios términos, «la mayor parte de Indios leales que han envejecido sirviendo al Soberano, y de pocos espańoles, pues su vecindario no llega a ocho familias» $y$, si bien no podemos hacer un balance de quienes eran en realidad, ni de su obra de gobierno, nos consta que denunciaron los agravios padecidos por los indios y exigieron al subdelegado y hacendado, Ramón Escobedo, los títulos de sus propiedades, ya que cuestionaban su legalidad. ${ }^{31}$

Abascal, ante las urgencias defensivas y sin alternativa al mayor ingreso fiscal del virreinato, optó por mantener el tributo. En el último confín del Perú, los indios se opusieron a continuar pagando el impuesto de capitación y uno de los lugares donde se ejerció mayor resistencia fue la provincia de Azángaro. A mediados de 1812, el intendente Manuel Quimper intentó revertir la situación. Exigió el regreso desde La Paz del curaca Manuel José Choquehuanca y organizó una fiesta cívica en Azángaro, con el subterfugio de celebrar la culminación de la visita de tributos y la bendición de banderas del regimiento de naturales que debían dirigirse a combatir al Alto Perú. En su transcurso, asumió que los indios se oponían a cualquier gravamen no acorde con el espíritu de la constitución y al principio de igualdad entre ciudadanos; $y$ - textualmente- escribió que "ciñéndose a la voluntad del indio, los más de estos se llaman Españoles, con la sujeción de la pensión de estos». ${ }^{32}$ Se optó por la propaganda coactiva y se vinculó la contribución personal con el usufructo de la tierra, amenazando con su privatización si persistía la resistencia a su abono. Si bien consta que los indios de Carabaya, Chucuito,

${ }^{30}$ Sala i Vila, 1992b y 1996.

${ }^{31}$ Hünefeldt 1982: 161-162.

${ }^{32}$ Oficio de Manuel Quimper al virrey, Puno, 3 de mayo de 1813. BNP, D 457, $\mathrm{N}^{\circ} 510$. 
Lampa y Huancané mostraron su predisposición a seguir pagando el tributo, el fiscal Miguel de Eyzaguirre se hizo eco de la resistencia indígena a seguir pagando el impuesto de capitación en Huarochirí, Yauyos, Ica y Azángaro. ${ }^{33}$ El intendente de Puno Dionisio Guzmán, señaló Azángaro como el foco de resistencia regional que perduró al menos hasta abril de 1813 y, a pesar de haberse avenido al abono de media tasa, el subdelegado solo pudo hacer efectiva la recaudación en cuatro pueblos y un ayllo, mientras que los indios de los pueblos de Azángaro y Asillo se negaron a pagar. ${ }^{34}$

El descontento de sectores constitucionalistas criollos e indígenas se exacerbó por el bloqueo sistemático del virrey y la Audiencia del Cusco a la aplicación de la Constitución de 1812 y la consecuente legislación liberal. Ambos grupos convergerían en la rebelión cusqueña en 1814, que se expandió hacia Huamanga, Huancavelica, La Paz y Arequipa. ${ }^{35}$ En junio de 1815, tras su derrota en Umachiri, el núcleo dirigente de la insurrección fue ajusticiado, y entre ellos el cacique de Chincheros Mateo Pumacahua, quien contaba con gran predicamento entre las huestes indígenas. Sin embargo, la lucha persistió y se radicalizó en el altiplano puneño y paceño, con focos activos hasta los primeros meses de 1816. Diversas montoneras — al mando de capitanes de partidas o, como en el caso de Tinta, bajo obediencia de mandos de extracción local, más o menos coordinadas con Ildefonso Muñecas - sostuvieron varias acciones armadas en la región ribereña al lago Titicaca y en los partidos de Abancay, Andahuaylas, Quispicanchis, Chumbivilcas, Tinta, Huancané, Lampa, Azángaro, Apolobamba, Larecaja, Pacajes y Omasuyos. El núcleo de Azángaro no sería derrotado hasta inicios del mes de junio de 1816, luego de varios enfrentamientos especialmente cruentos. La represión fue feroz, se aniquiló a varios dirigentes y se quintó a los presos en combate, fusilando a aquellos numerados con múltiplos de cinco. ${ }^{36}$ En todo ese tiempo,

33 Sala i Vila 1996.

${ }^{34}$ Archivo General de la Nación del Perú [en adelante AGNP], Derecho Indígena, leg. 40 C 8481813.

${ }^{35}$ O'Phelan 2017.

36 Sala i Vila 1992b: 273-278. 
Manuel José Choquehuanca fue un puntal de los intereses virreinales, y en reconocimiento a sus servicios militares sería nombrado en 1816 subdelegado interino y comandante militar de Chayanta. ${ }^{37}$ En resumen, el retorno al absolutismo, a partir de 1814, permitió al cacique volver a ejercer su preeminencia política local sobre los intereses comuneros, a tal punto que en 1819 se dirigió al subdelegado de Azángaro como curaca y propietario de la hacienda Choqueni, otrora puna de Omabamba, y le exigió que los indios matriculados en calidad de originarios del ayllu de igual nombre lo fueran como yanaconas de la hacienda, respetándose así sus derechos, lo que suponía exigir la vinculación de los indios a su propiedad, convirtiéndoles en una suerte de comunidad cautiva. ${ }^{38}$

Fruto de cierto consenso historiográfico, se ha asumido la crisis del cacicazgo indígena como consecuencia de la política hispana posterior a la rebelión tupamarista y a la política de Simón Bolívar. ${ }^{39}$ Sin embargo, nuestra hipótesis sostiene que durante el Segundo Liberalismo Hispano (1820-24) se vislumbraron con mayor claridad las consecuencias del reconocimiento de la ciudadanía a los indígenas. Fue en esa etapa, ahondando lo ya actuado entre 1812 y 1814 , cuando se abolieron las intermediaciones étnicas —en especial el Protector de Naturales - y los gobiernos étnicos locales y señoriales a consecuencia a la creación de ayuntamientos electivos en pueblos y ciudades, y la abolición del cacicazgo y sus derechos gubernativos y jurisdiccionales; al mismo tiempo que la creación de las milicias nacionales, finiquitaron la gestión de las levas étnicas por parte de los curacas. ${ }^{40}$ La aplicación efectiva de tales medidas, tras consultas a las distintas instituciones judiciales y representativas provinciales por

${ }^{37}$ Carta no 118 del virrey José Fernando de Abascal, marqués de la Concordia, a Pedro Cevallos, secretario de Gracia y Justicia, Lima, 20 de marzo de 1816, Archivo General de Indias, Audiencia de Lima, 752, $\mathrm{n}^{\circ} 2$.

38 Ramos Zambrano 2006: 628.

${ }^{39}$ O’Phelan 1997; Burga (1984: 75-77) pondría, entre otros, de ejemplo el caso de los Choquehuanca de Azángaro que habrían desaparecido, según él, literalmente tras la rebelión. Para mayores referencias a la realidad étnica del cacicazgo indígena, véase Garret 2009; O’Phelan 1997 y Serulnikov 2013.

40 Sala i Vila 2014. Las «milicias nacionales» se crearon bajo la Constitución de Cádiz, y en el Perú a partir de 1822. Para mayor referencia, Sala i Vila 2011. 
parte del virrey José de La Serna, fue una advertencia de las consecuencias del liberalismo para la población indígena, lo cual determinó afección o rechazo a este movimiento e inició la deconstrucción del entramado colonial que había preservado el gobierno propio y el acceso al usufructo de la tierra y recursos naturales a los indios. En el caso concreto de los Choquehuanca, Jacobsen apunta varias causas particulares que influyeron también en su decadencia: la relegación de cargos fiscales, el saqueo y destrucción de sus propiedades en la rebelión tupamarista y los múltiples litigios sucesorios en los que se enzarzaron. ${ }^{41}$

José Domingo Choquehuanca sería el exponente del sector de la elite indígena que se vincularía con los ideales y praxis del liberalismo. El que, según Clorinda Matto de Turner, era «indio peruano, de tez oscura, ojos de mirada centelleante, cabello negro, lacio y grueso, estatura pequeña, abdomen pronunciado, palabra firme, voz sonora y voluntad de acero; he ahí la persona», ${ }^{42}$ para unos, fue hijo de Roque Choquehuanca y María Mercedes León y Bejar, y para otros, quizás lo más plausible, del deán Gregorio Choquehuanca radicado en La Plata. Cursó estudios de derecho en la Universidad San Francisco Javier de Chuquisaca y de práctica forense en la Academia Carolina de Jurisprudencia. Luego, se graduaría en leyes en abril de 1809 y obtendría el doctorado en derecho civil y eclesiástico — secular y canónico- el 20 de agosto de 1811. Sin embargo, su título de abogado se hizo esperar hasta 1815, según el mismo Choquehuanca en 1814, debido a que el «destino desgraciado de haber nacido ilegitimo me impide la conclusión de mi carrera». ${ }^{43}$ Ya en la madurez, recordaba su formación basada en el estudio de «las instituciones de Justiniano expuestas por Kees o Vinio; en el derecho Real, cuya complicada legislación consta de las siete Partidas, e la recopilación de Castilla e Indias, de las diferentes ordenanzas, de los códigos

\footnotetext{
${ }^{41}$ Jacobsen 2013: 169.

42 Matto 1890: 275.

${ }^{43}$ El examen-disertación se efectuó el 22 de junio de 1811 y la petición de incorporación al Cuerpo de Practicantes Juristas tiene fecha de 20 de agosto de 1811. La afirmación de su ilegitimidad en carta a Pedro José Beyra y Escobedo del 29 de julio de 1814 (Ramos Zambrano 2012: 31-33).
} 
de Intendentes, de las pragmáticas, de las reales cédulas, de los autos acordados \& y del derecho canónico», concluyendo que los abogados de la década de 1840 poseían conocimientos en derecho romano y real español, canónico, natural y de gentes. ${ }^{44}$

A principios del siglo XIX, Chuquisaca se había convertido en el epicentro del cambio educativo y foco de la profunda reforma experimentada en la cultura jurídica y política dominante, al punto que los alumnos de su universidad tuvieron una proyección clave en la construcción política liberal y republicana de Argentina y Bolivia, al devenir en actores decisivos en los congresos revolucionarios y constituyentes de ambas naciones. ${ }^{45}$ Sabemos poco de la influencia de la escuela charqueña en los abogados peruanos; sin embargo, estamos en disposición de apuntar que fue, junto a las universidades del Cusco y Huamanga, un factor concluyente en la defensa de principios políticos y jurídicos constitucionalistas y codificadores que dominó en el ideario de buena parte de los abogados del sur andino, desde al menos el Primer Liberalismo Hispano hasta el fin de la Confederación Peruano-boliviana (1839), con especial incidencia en la Rebelión de $1814 .{ }^{46}$

José Domingo Choquehuanca vivió y se educó en ese ambiente profesional y político, el cual mutó hacia el liberalismo militante, además de determinar un cambio sustancial en el ejercicio profesional de la abogacía, cuando dejó de ser prioritaria la actuación al servicio de las corporaciones de Antiguo Régimen, para orientarse, junto a la labor ante los tribunales, hacia el foro parlamentario y la esfera pública en defensa de los intereses ciudadanos e individuales, en aras de la consecución de la igualdad de derechos y oportunidades basadas en principios meritocráticos. Choquehuanca no fue el único indígena que siguió estudios superiores luego de que la educación superior de los vástagos de la nobleza de origen incaico fuera posible a raíz de la Real Cédula

${ }^{44}$ Choquehuanca 1845.

${ }^{45}$ Gori 2016; Irurozqui 2016; Thibaud 2010.

${ }^{46}$ O’Phelan 2017. A falta de un estudio en profundidad, un análisis y contextualización de las universidades de Cusco y Huamanga, véase González González 2017: 448-465 y 707-720. 
de 11 de setiembre de 1766, la cual concedía a los indios el derecho a ingresar en las órdenes regulares, educarse en colegios y ser "promovidos según sus méritos y capacidad, a Dignidades y oficios públicos de estos reinos». ${ }^{47}$ Así, su primo Manuel José y el cacique de Tacna, Santiago Ara, se graduaron, igual que él, de abogados en Chuquisaca. ${ }^{48}$ Para ellos, Justo Sahuaraura fue el exponente en sus estudios de teología y derecho canónico, en su caso, en el Real Convictorio de San Antonio Abad del Cusco, doctorándose en 1808, ejerciendo en 1840 de juez de paz eclesiástico del Obispado del Cusco. ${ }^{49}$

No nos consta que José Domingo Choquehuanca ejerciera de abogado, aunque no podemos descartar que su formación fuera un factor determinante para el desempeño de sucesivos cargos administrativos y representativos. En 1817, era Justicia Mayor de Azángaro, de cuya gestión solo hemos documentado su autoría de un inventario de rentas de censos destinadas entonces al pago de tributos de la comunidad y que se querían derivar a la creación de una escuela local. ${ }^{50}$ En 1821, durante el Segundo Liberalismo Hispano (1820-24), sería escogido elector municipal de Azángaro, ${ }^{51}$ lo que indica su capacidad de insertarse en los nuevos mecanismos del gobierno representativo, que demandaba capacidad de alcanzar consensos y apoyos entre los votantes, fuera cual fuera su origen étnico.

${ }^{47}$ Rodríguez Casado y Pérez Embid 1947: 122v y 123. Anteriormente la educación de los hijos de nobles se dio en los Colegios del Príncipe en Lima o San Borja en el Cusco (Alaperrine-Bouyer 2007)

${ }^{48}$ Choquehuanca obtuvo el grado de bachiller en Cánones el 2 de diciembre de 1803 y el grado de abogado el 3 de mayo de 1811(Abecia, 1939: 357 y 361). Un estudio del papel intelectual de Ara en Guibovich 1990.

${ }^{49}$ Flores 2001: 26; Carrasco 1840: 231.

${ }^{50}$ Instrucción que contiene los principales réditos a beneficio de la ayuda de tributos para el establecimiento de escuela, teniente Domingo Choquehuanca, Azángaro, 17 de marzo de 1817, Archivo del Instituto Riva-Agüero [en adelante AIRA], Fondo Denegri Luna, 1670.

${ }^{51}$ Acta de las elecciones y juramento del Ayuntamiento Constitucional de Azángaro, 9 de diciembre de1821, 23 de diciembre de1821 y 1 de enero de 1822, Archivo del Museo Nacional de Arqueología e Historia del Perú, Mss. 001691. 
Entre tanto, los comuneros dirimieron ante la Audiencia Nacional del Cusco en 1822 sus diferencias con el cacique Manuel José Choquehuanca, ${ }^{52}$ mostrando su capacidad de actuación legal corporativa, en parte por la libertad de acción que les garantizaba la gestión de bienes comunales, estimados a fines de la década de 1820 en unas 1.300 cabezas de ganado. ${ }^{53}$ Las guerras de independencia, a diferencia de las rebeliones de $1780-83$ y de 1814-16, no hicieron especial mella en Azángaro; al contrario, la zona vivió una época de relativa bonanza económica al surtir las demandas de avituallamientos de los ejércitos reales. ${ }^{54}$

\section{LOS CHOQUEHUANCA EN LOS TIEMPOS DEL CAUDILLISMO}

José Domingo Choquehuanca lograría cierta fama al dedicar una arenga lírica a Bolívar en el trascurso de su recepción, la cual se le ofreció en Pucará el 2 de agosto de 1825. Ese mismo año, se acusó y juzgó al cacique Manuel José Choquehuanca de dar vivas al monarca y a España, condenándole a una multa de 100 pesos y a las costas procesales. Sin embargo, logró atenuar la pena al humillarse y reconocer haber actuado en estado etílico, junto al apoyo de un viejo compañero de armas realistas, el arequipeño y entonces prefecto de Puno Domingo Tristán, quién le defendió ante el secretario de Bolívar. Manuel José y su "Viva al Rey» se nos aparece como una expresión casi desesperada ante un mundo que se desvanecía junto a las bases de su poder y prestigio señorial y étnico, al emerger una república que prometía ciudadanía, igualdad y gobierno electivo al conjunto de los ciudadanos independientemente de su adscripción étnica. Tal como había expresado alguna vez su tío José a los comuneros, solo el rey podía dar y quitar el título de curaca, una fuente de poder y legislación que desapareció con la construcción del proyecto republicano. En consecuencia, su mundo y todo aquello por

\footnotetext{
52 Acusaciones del pueblo de Azángaro contra su cacique recaudador coronel don Manuel Choquehuanca, Audiencia Constitucional del Cusco, 1822, ARC, Real Audiencia. Causas Criminales, leg. 145.

53 Choquehuanca 1833: 18.

${ }^{54}$ Jacobsen 2013: 98-99.
} 
lo que había luchado desaparecía aceleradamente, como la presteza con que el virrey La Serna zarpó rumbo a la península poco después de la capitulación en Ayacucho, dejando atrás y a su suerte a todos cuantos lucharon por la causa realista.

Manuel José y José Domingo Choquehuanca se situaron en posiciones distintas: uno realista y el otro bolivariano; lo que quizás pueda interpretarse como una estrategia familiar para adecuarse a los vaivenes políticos de las primeras décadas del siglo XIX, cuya finalidad sería mantener sus posiciones preeminentes a nivel regional fuera cual fuera la facción dominante. ${ }^{55}$ Ambos fueron electos representantes parlamentarios, un rara avis entre los indios dentro de la política peruana del siglo XIX, ya que solo lo lograron además Justo Sahuaraura, diputado por Aymaraes en 1826, Mariano García Pumacahua, hijo del cacique de Chincheros ajusticiado en 1815, e Ignacio Quispe Ninavilca, cacique de Huarochirí, en 1828 en representación de Cusco y Lima respectivamente. ${ }^{56}$

El advenimiento de la República en el sur andino no cerró un ciclo; más bien la conflictividad política se mantuvo. La región se convirtió en el escenario preferente de las luchas entre caudillos, suerte de metáfora dramática de la falta de consensos políticos, una realidad que culminaría en el fracasado ensayo de la Confederación Peruano-boliviana (1836-39). Manuel José Choquehuanca superaría su subjetiva percepción de ser protagonista de un tiempo agónico, y en 1832 sería electo diputado por Azángaro, si bien no sin cierta oposición en su provincia de la que se hizo eco el periódico La Voz de Puno. ${ }^{57}$ En sus páginas y bajo la firma de unos «azangarinos», se cuestionó la legalidad de su acta de diputado por varios motivos: ser «Coronel de antes del año 25 , y ahora flamante liberal»; haber nacido en Bolivia; ser considerado autor de un asesinato alevoso en Carabuco en 1823; y por «delito de sedición en Azángaro en 1825: sin haber logrado ser absuelto». Datos y hechos que habían sido, en parte, incorporados a sus credenciales por el Colegio Electoral, aunque

\footnotetext{
${ }^{55}$ Ramos Zambrano 2006: 617-639.

56 Águila 2012: 19 y 2013.

57 Paredes 1832: 25.
} 
no fueron aceptados puesto que «la Cámara como en muchas otras cosas procedió de hecho y no de derecho». ${ }^{58}$ Las muestras de animadversión por parte de grupos locales se repitieron en 1833 cuando el periódico cusqueño El Cocacho insertó una carta de los habitantes de Picotani, Catacora y Chata en Azángaro en la que le tildaban de "godo pertinaz y tirano», y junto a su primo José Domingo, se les descalificaba para ejercer las representaciones respectivas de diputado y senador. ${ }^{59}$ Años después, Manuel José Choquehuanca fue partidario de la Confederación, aunque sus diferencias con Santa Cruz le llevarían al exilio en Bolivia. ${ }^{60}$

Choquehuanca fue elegido diputado por Puno en 1825, luego sería miembro de la Asamblea Constituyente de 1826 y uno de los 52 firmantes en pro de la permanencia de Bolívar en Perú. ${ }^{61}$ A continuación, integraría la Junta Departamental de Puno (1827-32) en calidad de diputado por Azángaro, institución en la que sería sucesivamente secretario (1828) y puntualmente presidente. ${ }^{62}$ Hombre curtido en las actividades políticas representativas y, asimismo, ávido de cargos administrativos, su visión política trascendería en las obras destinadas a describir o reflexionar sobre la realidad que le tocó vivir y gestionar. En ese aspecto, nos ha legado dos textos: Ensayo de estadística completa de la provincia de Azángaro (1833) y Complementos al régimen representativo (1845), obra dedicada al general Ramón Castilla. ${ }^{63}$ Poco sabemos del resto de su producción escrita, del cual se ha conservado el rastro de un texto burocrático titulado «instrucción que contiene los principales réditos

${ }^{58}$ La Voz de Puno. Núm. 42, sábado 19 de enero de 1832.

${ }^{59}$ O'Phelan 1997: 76-77.

60 Frisancho 1953: 12.

61 Gaceta de Gobierno. Núm. 25, t. 9, 25 de marzo de 1826.

62 En 1828 estaba integrada por José María Recavarren, presidente, José Ignacio Evia y José Domingo Choquehuanca diputados por Azángaro, José Faustino Dazal y Marcos Goyzueta por Lampa, Manuel Pino y Gregorio Prieto por Chucuito [AIRA, Fondo Denegri Luna-1670].

63 Choquehuanca 1833. Versión original digitalizada disponible en https://babel. hathitrust.org/cgi/pt?id=yale.39002015363808;view=1 up;seq=1, consultada 15.9.2018. Choquehuanca 1845. Versión original digitalizada disponible en http://curiosity.lib. harvard.edu/lap/catalog/11-007793943, consultada 15.9.2018. 
a beneficio de la ayuda de tributos y para el establecimiento de escuela para este efecto», fechado en Azángaro el 17 de marzo de 1817. Por otro lado, también hemos recopilado alguna correspondencia oficial, con la que, según Clorinda Matto de Turner, mantuvo comunicación con intelectuales como «Paz-Soldán, Ureta, Luna Pizarro, Vigil, Felipe Pardo, José María Químper» ${ }^{64}$. Matto añadiría que colaboró con este último en La Reforma de Arequipa, la cual aprovechó como tribuna para expresar sus ideas republicanas, un dato que no hemos podido constatar. A continuación, analizaremos los dos textos y los situaremos dentro de su acción política y su voluntad de medrar en cargos administrativos.

\section{EL ENSAYO DE ESTADÍSTICA COMPLETA DE LA PROVINCIA DE AZÁNGARO}

En Puno, la Comisión de Estadística de la Junta Departamental abordó la necesidad de recopilar la información del conjunto de la región, un ejercicio que se encargó a múltiples actores locales, tales como fiscales, gobernadores civiles y autoridades eclesiásticas. A José Domingo Choquehuanca se le encargó la elaboración de la Estadística de la provincia de Azángaro, siendo esta la única provincia en que se culminó la labor de recogida y análisis de información. En las otras se fracasó, según él mismo, por las dificultades para obtener información de los párrocos de Lampa, Chucuito y Huancané, y la nula colaboración de las autoridades de Carabaya. ${ }^{65}$ La prensa regional no pudo abstraerse a tal realidad, y el Peruano del Sud se hizo eco en 1829 de las dificultades de la Comisión de Estadística para indagar datos en todas las provincias, señalando como causa que al haber sido «educados todos bajo el coloniaje espańol, no era posible que se nos hubiesen dado los conocimientos, que en otras partes del globo se han repartido abundantemente entre los libres». ${ }^{66}$ Se proponía una fórmula específica para aunar esfuerzos, encargando a los revisitadores de tributos el preceptivo recuento fiscal, más el censo

64 Matto de Turner 1890: 274.

${ }^{65}$ Oficio de José Domingo Choquehuanca al Prefecto de Puno, 29 de setiembre de 1830, AIRA, Fondo Denegri Luna-1670.

${ }^{66}$ El Peruano del Sud, $\mathrm{n}^{\circ} 17$, jueves 22 de octubre de 1829. 
de población y los pormenores de topografía descriptiva y física. Y si bien no se logró una estadística completa de todo el departamento, se puede considerar en parte un éxito la actuación de la Junta Departamental de Puno respecto a las restantes instituciones representativas regionales, ya que se actualizó el censo electoral, al punto que sería el único departamento que efectuó las elecciones en 1828 según datos fehacientes, entre tanto en el resto del territorio nacional hubo de valerse del censo colonial de $1792 .{ }^{67}$

Choquehuanca estructuró su texto en varios apartados dedicados a las características del reino vegetal y mineral, la economía regional y el estado social, enumerando los pueblos y prestando atención a sus peculiaridades y autoridades, para avanzar una serie de disquisiciones sobre las causas de la decadencia regional. La obra ha sido suficientemente analizada desde dichos aspectos, por lo que nos limitaremos a abordar sus consideraciones relativas a las categorías sociales, las leyes y la cultura política que llevaba implícita. ${ }^{68}$

Amigo de las clasificaciones sociales y económicas, José Domingo Choquehuanca dividió a los azangarinos en función de su riqueza y de su pertenencia étnica. Solo un propietario y dos eclesiásticos poseían bienes cuyo valor superaba los 50.000 pesos; por su parte, los acomodados o «que pueden vivir sin necesidades» se subdividían en tres clases: los curas, unos 13 hacendados o propietarios antiguos y los nuevos propietarios, algunos indígenas y otros mestizos (agricultores o comerciantes). ${ }^{69}$ Por último, cabe señalar, que si bien incorporaba a los indios entre los propietarios, tendía a equiparar indígena y pobreza. ${ }^{70}$ Se refería a los indios como a los otros y evitaba autodefinirse étnicamente; aunque se infiere por el tono de sus comentarios que se situaba en un espacio de intermediación, tanto por su capacidad de describir la realidad social puneńa, como por la búsqueda de remedios para resolver la situación

${ }^{67}$ Petición de varios diputados, entre ellos José Domingo Choquehuanca, Lima, 21 de abril de 1826, en Colección de Leyes 1832: 212-217.

${ }^{68}$ Jacobsen 2013: 183-245.

${ }^{69}$ Choquehuanca 1833: 60.

${ }^{70} \mathrm{Ib} .: 59-60$. 
del indio. Los describía como criados en el campo, junto a los animales, consumiendo únicamente productos naturales. Textualmente, afirmaba que el indio «se cría robusto y de temperamento sano, por lo que tiene una completa expedición en sus facultades intelectuales y en las orgánicas de su físico; y por esto es que son muy raros los mudos y dementes»; ${ }^{71} \sin$ embargo, según su opinión, en su mayoría de edad, primaba su subordinación, cuya raíz era su condición de contribuyente, que le convertía en el último escalón social, incluso por debajo de los criados. Sufrían su condición de "abatimiento y degradación», convencidos "que no han nacido con más destino que el de ser esclavos» ${ }^{72}$, obligados a prestar servicios personales «sin embargo de los decretos del tiempo del gobierno español y de los del gobierno de la Independencia y de las garantías constitucionales» ${ }^{73}$ y a abonar aranceles eclesiásticos desorbitados.

Se detuvo en describir la vestimenta de hombres y mujeres, detallando las particularidades locales, mostrando las distinciones entre los indios del común y los principales, quienes lucían, en fiestas y rituales, capas de paño de Quito heredadas de generación en generación. Si bien habían quedado en desuso el uncu y el acso, los indios seguían vistiendo prendas étnicas diferenciadas, no tanto por opción propia o seńa de identidad, sino como resultado de que «los subdelegados, curas, recaudadores y demás funcionarios, no permiten a los indígenas jóvenes vestir con decencia... encargándoles que no debían vestirse como los españoles», porque consideraban que los indígenas que se vestían como españoles se hacían orgullosos y desobedientes. Este es el común sentir de los mandatarios en los años inmediatos a la Independencia. ${ }^{74}$

Añadía varias valoraciones de tintes regeneracionistas. Les describía en sus viviendas, en la más absoluta carencia de higiene corporal. Describía una realidad social dominada por el alcohol y unas relaciones personales en que imperaban el insulto, la rińa y la pelea, de la mano de la pobreza, el abigeato, la ignorancia y la abyección por su credulidad de supers-

${ }^{71}$ Ib.: 68 .

${ }^{72} \mathrm{Ib}$.

${ }^{73} \mathrm{Ib}$.

${ }^{74}$ Ares 1999. 
ticiones y augurios. Jacobsen considera la posición de José Domingo Choquehuanca respecto a los indios de esperanzadora y moralizante, ${ }^{75}$ entre tanto que Cecilia Méndez le sitúa cercano a quienes sintieron «la necesidad de mantener a los indios tal cual». ${ }^{76}$ Para añadir más elementos de análisis, me interesa destacar que la desoladora realidad que describía se revertiría — según su propuesta regeneracionista — cuando se promoviera la arquitectura civil, la higiene y la educación, entendida esta última como la clave del progreso. En este último sentido, mostraba preocupación por la decadencia económica provincial de Azángaro, atribuyendo el declive a varias causas: la política de los monarcas absolutos, que, según él, desdeñaron favorecer el progreso y la educación, lo que mantuvo a los azangarinos en la ignorancia; el impacto de las revoluciones de 1780 y 1814 y las guerras de Independencia. La regeneración podría lograrse si se incentivaba la educación, aunque la tarea era ingente, ya que se hallaba en estado crítico. No existía ni una sola escuela pública, por lo que la formación de menores era un asunto de iniciativa privada, llevada a cabo por "maestros inmorales e ignorantes», ${ }^{77}$ entre tanto ciertos sectores indígenas optaban por educar a sus hijos en Arequipa con el objetivo de que dominaran la lengua castellana y las bases de las relaciones y actividades económicas y comerciales. ${ }^{78}$ Además, era especialmente crítico con los programas de estudios superiores, a los que dedicaba serias descalificaciones: «la gramática latina tan funesta al mundo entero, no ha servido de otra cosa, que, de paralizar, el curso de la ciencia»; ${ }^{79}$ "la filosofía enseñada en la parte más estéril, y quimérica, no ha podido producir fruto alguno»; ${ }^{80}$ la teología escolástica "tenida por la ciencia más sublime, ocupaba inútilmente, la contracción de los mayores talentos». ${ }^{81}$ Sin embargo, a lo apuntado, sus críticas más feroces

75 Jacobsen 2013.

${ }^{76}$ Méndez 1993: 25 y n. 56.

77 Choquehuanca 1833: 64.

${ }^{78}$ Ib.: 61.

${ }^{79} \mathrm{Ib}$.

${ }^{80} \mathrm{Ib}$.

${ }^{81} \mathrm{Ib}$. 
se dirigían a la forma cómo se había enseñado el derecho, al seguirse prestando atención «al romano y al real... no inspiraba más ideas que las de una aristocracia insoportable y las de la inviolabilidad del absolutismo, y mil ideas de servidumbre y de leyes contrarias a los principios de utilidad común»; ${ }^{82}$ al canónico el cual "por el terrorismo espantoso de sus grandes excomuniones preparaba a los espíritus débiles a la más degradante sumisión, para que nunca se reclamasen los avances que se habían hecho, sobre los derechos de la potestad civil». ${ }^{83}$ Tales premisas, imperantes en la educación impuesta durante el dominio colonial estaban «en oposición con la libertad de pensar». ${ }^{84}$ Pendiente de evaluarse la labor gubernativa de Choquehuanca, algunos datos apuntan a su interés por promover la educación de la juventud puneña, influido por la obra de José Joaquín Mora, Curso de Lógica y Ética según la Escuela de Edimburgo (Lima, 1832), de la que fue subscriptor durante su etapa de diputado residente en Lima. ${ }^{85}$

Sin mencionarlo explícitamente, se hacía asimismo eco de la resistencia a los cambios en la cultura jurídica que se impusieron en Charcas cuando se innovó bajo la influencia de la Scienza della legislazione de Filangeri en la práctica procesal de su Audiencia, además del sistema educativo por obra de la Universidad de San Andrés y en la Academia Carolina de Jurisprudencia, instituciones que le habían influido en su etapa de formación. ${ }^{86}$ Podemos apuntar que Choquehuanca escribió al influjo de su experiencia en Charcas, criticando la persistencia de la escolástica y las leyes antiguas que frenaban la construcción de un proyecto liberal y republicano. ${ }^{87}$ Se mostraba crítico con el poder judicial, debido

${ }^{82}$ Ib.: 64-65.

${ }^{83}$ Ib.: 65 .

${ }^{84} \mathrm{Ib}$.

${ }^{85}$ Mercurio Peruano. Núm. 1501, 28 de noviembre de 1832, 2-3, citado por Monguió 1967: 141.

${ }^{86}$ Portillo 2009; Morelli 2007; Gori, 2010; Thibaud 2010; Sala i Vila 2016a.

${ }^{87}$ Somos conscientes de que su caso no siempre puede ser extrapolable al conjunto de los indígenas formados en Charcas, ya que Santiago Ara, cacique de Tacna, si bien atesoró una no desdeńable biblioteca especializada en obras de derecho, no mostró especial interés en adquirir obras de inspiración ilustrada o liberal (Guibovich 1990). 
a la carencia de "juez de derecho», ${ }^{88}$ que había condicionado la administración de justicia ejercida por subprefectos sin formación legal alguna, lo que condicionó «arbitrarias aplicaciones de las leyes». ${ }^{89}$ Añadía que en el quinquenio evaluado, no se había incoado causa criminal alguna, a pesar de haberse perpetrado varios delitos penales; además de que solo se habían dirimido un reducido número de pleitos civiles, de baja cuantía, entre tanto los disensos entre indígenas fueron resueltos por los jueces de paz «las más veces mal, por la ignorancia o por la malicia de los juzgadores». ${ }^{90}$

A su vez, puso el énfasis en la fragilidad política y deficiente gestión de las nuevas autoridades durante el quinquenio transcurrido desde la Independencia de Puno en 1824, ya que se habían sucedido siete subprefectos, que gobernaron durante cortos periodos o dedicaron poca atención en "cumplir los encargos de la ley», ${ }^{91}$ motivo que había impedido avance alguno en la región, y se exclamaba que «se ha sacrificado el bien general de los pueblos, al bien particular». ${ }^{92}$ Las mismas disonancias entre leyes y gobierno las constataba en los gobernadores distritales y en las municipalidades; si bien era partidario de que «todas las instituciones caminan a su perfección por el aprendizaje», ${ }^{93}$ ponía sus esperanzas en estas para enfrentar y limitar los abusos de subprefectos, gobernadores y curas, observando rasgos de «desarrollo del espíritu público; y de la civilización, de aquellos ciudadanos que jamás habían tenido parte en los intereses públicos y particulares de sus pueblos». ${ }^{94}$

El Ensayo de Estadistica surgió en un contexto de cambios sustanciales en la práctica política, que procuraron incorporar la estadística, entendida como ciencia del estado e instrumento imprescindible para

\footnotetext{
${ }^{88}$ Choquehuanca 1833: 72.

${ }^{89} \mathrm{Ib}$.

${ }^{90}$ Ib.: 71-72.

${ }^{91}$ Ib. 71.

$92 \mathrm{Ib}$.

${ }^{93} \mathrm{Ib}$.

${ }^{94}$ Ib.: 71-72.
} 
el ejercicio del poder. ${ }^{95}$ El objetivo era caracterizar y definir la sociedad a través de oficinas de registro y administración estadística, para poder intervenir y moldearla, según determinados intereses políticos. ${ }^{96} \mathrm{Si}$ bien el constitucionalismo reconocía al ciudadano y la libertad individual, se buscaba en la práctica definir al «hombre medio», lo que en realidad era "una ficción analítica de la estadística», ${ }^{97}$ que abría el camino a la intervención política para reconducir las patologías sociales —higiénicas, morales, delictivas - e imponer formas de disciplina social esenciales para lograr el progreso nacional..$^{98}$

Aunque durante el reformismo borbónico se dieron pasos fundamentales para mejorar los sistemas de información, en general, y a excepción del censo de población de 1792, tuvieron fines fiscales — visitas de tributos quinquenales- sin que se llegara a llevar a cabo catastro alguno. Cabe situar en el Liberalismo Hispano los primeros antecedentes de la elaboración de bases de datos de estadísticas demográficas y económicas con el objetivo de elaborar un censo electoral actualizado y contar con una prospección de la realidad local que permitiera diseñar proyectos de desarrollo regional. Dicha tarea se encomendó a las Diputaciones Provinciales —Lima y Cusco entre 1812 y 1814, y 1820 y 1822—; Arequipa, Ayacucho, Cusco y Puno entre 1822 y 1824 . Sería en tal contexto cuando Hipólito Unánue publicó en 1813 en El Verdadero Peruano los primeros artículos que incorporaban la acepción estadística en su título. En ellos, recopiló datos extraídos de las Guias Políticas del Perú, editadas por el mismo desde 1793, para facilitar, según sus palabras, la labor de la Diputación Provincial, que debía afrontar «la formación del censo y estadística del Perú, sin los cuales no es posible dar un paso acertado en los mayores y más útiles proyectos de utilidad pública».9

\footnotetext{
${ }^{95}$ Desrosières 2004; Hacking 1991.

${ }^{96}$ Un análisis en tal sentido en Ragas (2008 y 2013); focalizado en el censo de Lima 1860 en Peloso y Ragas (2001).

97 Mayer 2014.

${ }^{98} \mathrm{Ib}$.

${ }^{99}$ Unánue 1813.
} 
José de Larrea y Loredo, diputado, presidente del Primer Congreso Constituyente y ministro de Hacienda (1825 y 1826), publicó en 1826 las Bases para la estadística del Perú. ${ }^{100}$ En el texto, incluyó un compendio histórico de la ciencia estadística, con especial referencia a su adopción por los pequeńos estados alemanes, la Francia de Luis XIV o de Luciano Bonaparte, la Inglaterra del s. XVII o su incorporación en la reforma fiscal liberal española. ${ }^{101} \mathrm{Su}$ objetivo, según el autor, era el cálculo de la riqueza territorial sobre la base de recopilar datos demográficos y de la producción agrícola, industrial y comercial: «esta operación se llama estadística», para "conocer la riqueza y fuerza de un Estado», y superar el hecho de que "hasta ahora carecemos de un plan de ella». ${ }^{102}$

Se trató de un proceso paralelo al de la construcción de estados liberales en otros países de América Latina, como ejemplifican los casos de Colombia, Argentina o México: una modernidad que, según Jesús Bustamante, contradice las tesis historiográficas que defienden la persistencia de un atraso político y estatal generalizados en la América Latina posindependencia. ${ }^{103}$ En el caso del Perú, la difusión de noticias estadísticas por la prensa de la época indica la toma de conciencia de su importancia en el ejercicio de la política y la observación de su aplicación en países vecinos, como muestra la reedición en La Prensa Peruana de la

${ }^{100}$ El Peruano. Núms. 44, 45, 46, 48, 49, 51, 57, 60 y 61, 1, 4, 8, 15, 18 y 25 de noviembre y 13,16 y 27 de diciembre de 1826. Salinas (2001) atribuye el texto a Andrés Salazar y Muñatones.

${ }^{101}$ En concentro citaba la orden de Luis XIV para que los intendentes informaran del estado político, civil, militar y religioso, que en parte fueron recopilados en la obra de Boulin Viller, Estado de Francia; la Descripción general y topográfica del ministro Luciano Bonaparte; el Breve ensayo de la aritmética politica de Dyarniere; y el Ensayo estadístico de Mourgue; se refería al Plan General de Pitt, base de la fiscalidad inglesa; y para el caso español, se remitía a las disposiciones de las Cortes sobre la Contribución directa (El Peruano. Núm. 45, 4 de noviembre de 1826).

${ }^{102}$ El Peruano. Núm. 44, 1 de noviembre de 1826.

${ }^{103}$ En tal sentido Bustamante cita la temprana creación de instituciones estatales dedicadas a la estadística, como fueron la Oficina Central de Estadística de la Gran Colombia (1821), el Registro Estadístico del Estado de Buenos Aires (1821) y la Sociedad Mexicana de Geografia y Estadistica (1833) (Bustamante 2014: 9-83). 
Descripción geográfica y estadística de Bolivia, originalmente publicada en el periódico oficial boliviano Iris de la Paz en 1829. ${ }^{104}$

Para los prohombres que iniciaron la construcción nacional del Perú, era necesario sentar las bases de gobiernos que construyeran un país con un poder político representativo y próspero, lo que a su entender requería abordar la elaboración en primer lugar de un censo de población, a modo de instrumento esencial para organizar el sufragio electoral y recopilar la mayor información posible destinada a generar políticas de fomento económico y social, y, junto a ello, abordar una reforma fiscal acorde con la realidad económica y los principios liberales vigentes. El censo estuvo entre las preocupaciones de quienes sentaron las bases del Ministerio de Hacienda, Hipólito Unánue y José Larrea y Loredo. El primero firmó el 1 de mayo de 1826 el decreto ordenando levantar el censo de población con fines electorales, ${ }^{105} \mathrm{y}$ el segundo dispuso incluir en él los datos fiscales. ${ }^{106}$ Según Paul Gootenberg, los resultados parciales del censo de 1826 fueron publicados en La Prensa Peruana y El Telégrafo de Lima. Añadamos a lo anterior la afirmación del general Luis José de Orbegoso, quién destacó en sus memorias haberse dedicado durante su tiempo de prefecto de La Libertad (1824-28) a efectuar visitas periódicas al departamento bajo su mando "para formar una completa estadística de todos los lugares y distritos, observar las costumbres de sus habitantes, promover su ilustración». ${ }^{107}$ Sin embargo, no fue posible culminar la labor para el conjunto del país, un fracaso reconocido por Larrea y Loredo al afirmar que

podía haber emprendido mejoramientos considerables en la hacienda del Estado, fundados en los más célebres sistemas de contabilidad y otras prácticas adoptadas por la civilización moderna, atemperándolos a las instituciones de la República, índole, miras, pasiones e intereses de sus habitantes, pero no habiendo recibido a tiempo la estadística de los departamentos como

${ }^{104}$ La Prensa Peruana. Núms. 15, 18, 87. 39. 40 y 49, 1829 (AIRA, Fondo Denegri Luna).

${ }^{105}$ Archivo Digital de la Legislación del Perú.

${ }^{106}$ Larrea y Loredo 1827.

${ }^{107}$ Citado por Peralta 2016:189. 
base esencial sobre que habían de fundarse los planes y reformas, a causa de la mala inteligencia de unos, indolencia de otros, y más ciertamente por la premura extraordinaria del tiempo se han frustrado mis designios, y no permitido sino la emisión de unos cuantos decretos, que no han mudado en la sustancia los abusos inveterados del régimen colonial. ${ }^{108}$

En años sucesivos, las Juntas Departamentales asumieron la competencia en la recopilación de informaciones estadísticas. La producción fue desigual, al punto que solo serían publicadas en la década de 1830 las de Lima y Azángaro. ${ }^{109}$ En la primera, Estadistica histórica, geográfica, industrial y comercial de los pueblos que componen las provincias del Departamento de Lima (1839), José María Córdova y Urrutia refería «la influencia directa que la Estadística tiene en la felicidad de los estados, ahora se calcule sobre su riqueza actual, ahora sobre los medios de adelantarla, ahora en fin, sobre las medidas que deben adoptarse para crear nuevos recursos y obligar a la tierra desarrolle los tesoros que abriga en su seno». ${ }^{110}$ Entre tanto en su obra, José Domingo Choquehuanca recalcaba en la exposición inicial cómo tuvo que "correr y recorrer la provincia», ${ }^{111}$ convenciendo a los remisos que la finalidad de los datos estadísticos no era meramente fiscal «sino para promover la felicidad y prosperidad de ellos [los pueblos]». ${ }^{12}$ Los diputados de la Junta Departamental de Puno no dudaron en defender teóricamente la importancia de la estadística al insistir textualmente: «es el conocimiento físico y moral que se da de un estado; o la suma de conocimientos morales, físicos y matemáticos, con que se presenta un estado al conocimiento de las naciones y ante los mismos hijos de aquel». ${ }^{113} \mathrm{Su}$ finalidad era dotar de instrumentos políticos a las autoridades:

${ }^{108}$ Larrea y Loredo 1826.

${ }^{109}$ Gootenberg 1995: 16-20 y n.20.

${ }^{110}$ Córdova y Urrutia 1839, III.

${ }^{111}$ Choquehuanca 1833: 1 .

${ }^{112} \mathrm{Ib}$.

${ }^{113}$ El Peruano del Sud. Núm. 17, jueves 22 de octubre de 1829. AIRA, Fondo Denegri Luna. 
es la antorcha que iluminando a un cuerpo legislativo le hace decretar leyes sabias y justas: ella es el anteojo, con que el Jeneral...arreglar el plan de sus operaciones; ella dirije los pasos de los sacerdotes de la naturaleza, que velando en el santuario de la salud pública se ocupan de curar las dolencias de la humanidad enferma: ella en fin es el cuadro pintoresco, con que una nación atrae en su torno al hijo de lejanas naciones, aumentando con esto su población, para dar impulso a las artes, a las ciencias y al comercio. ${ }^{114}$

La estadística era considerada una herramienta para desarrollar la legislación en aras de construir la nación ideal, definir las bases de la defensa militar, mejorar las condiciones sanitarias e higiénicas de la población, y, vía la propaganda, atraer migración que permitiera regenerar la economía y promover la ciencia vista como base del progreso. En todos ellos, se puede constatar su fe en la estadística como base de la felicidad y prosperidad, nuevas promesas de una acción política que partía de la necesidad de conocer e inventariar la realidad nacional para sentar las bases del progreso.

Pero nuestro objetivo, además de señalar su conocimiento de los caminos sugerentes que tomaba la defensa de lo público de la mano esta vez de la estadística, entendida como apuntamos a modo de ciencia de Estado, es mostrar, que, entre otros fines, su labor y texto editado le sirvieron para intentar medrar en la política. Tras su etapa en la Junta Departamental, volvería ocupar puestos de representación nacional. Durante la primera presidencia de Agustín Gamarra (1829-33), ${ }^{115}$ fue electo senador por Puno en 1832, ocupando en la Alta Cámara el puesto de secretario suplente en 1833, ${ }^{116}$ y Consejero de Estado en 1833; en 1834 fue de nuevo representante al Congreso, si bien este no llegó a reunirse a causa del levantamiento de Felipe Santiago Salaverry. ${ }^{117}$ Sabemos poco de su labor parlamentaria, salvo referencias vagas de defender la creación

${ }^{114} \mathrm{Ib}$.

${ }^{115}$ Peralta (2016) ha llamado la atención sobre el ejercicio de la política por el presidente Gamarra desde las bases de un modelo de patronazgo institucional y sentando las bases de la «dominación contemporánea mediante la administración».

${ }^{116}$ Paredes 1832: 22.

${ }^{117}$ Ramos 2012: 65. 
de un obispado en Puno, la abolición del fuero eclesiástico y la extinción de los servicios personales de los indios. El único dato fehaciente que he documentado es una proposición de ley para reformar, en parte, la legislación comercial y favorecer la intervención privativa de peruanos o extranjeros ciudadanos casados con peruanas, lo que le situaría entre quienes defendieron presupuestos proteccionistas. ${ }^{118} \mathrm{Si}$ retomamos las referencias sobre los remitentes de sus cartas, aportados por Clorinda Matto, ello nos permite concluir que en la década de 1830 se relacionó sobre todo con la bancada liberal.

Entre 1834 y 1839, ocupó varios cargos fiscales y gubernativos provinciales. El Ensayo de estadistica fue durante ese tiempo el aval del que se valió para medrar en la administración estatal. En 1834, ofrecía al gobierno 400 ejemplares impresos, a un costo de 12 reales cada ejemplar, la sexta parte para sí y el resto destinado a la tesorería de Puno. El gobierno adquirió 75 ejemplares y los remitió a las distintas provincias, ${ }^{119}$ acompañados de una circular que fijaba el texto de modelo a seguir por los apoderados fiscales cuando levantaran la estadística provincial y las matrículas respectivas. ${ }^{120}$ El 9 de julio de 1834, Luis José Orbegoso lo nombró apoderado fiscal para la actuación de la matrícula de indígenas y castas de la provincia de Chucuito. Ahí entró en contradicción con los intereses de otros demandantes locales de puestos y beneficios. Como mostró la contraoferta de José María Recabarren, dispuesto a llevarla a cabo gratuitamente y haciendo valer su experiencia de subprefecto. A la postre, los vaivenes políticos determinaron su substitución por órdenes directas del general Domingo Nieto, lo que le llevó, en octubre de 1834, a denunciar la invasión de competencias y a pedir su suspensión. ${ }^{121}$ Según Christine Hünefeldt, en 1834, desde

${ }^{118}$ Proposición de ley de 2 de diciembre de 1832 firmada por Manuel Tellería, presidente del Senado, Francisco de Paula G. Vigil, vicepresidente de la Cámara de Diputados, José Domingo Choquehuanca, senador secretario suplente y José Goycoechea, diputado secretario al presidente de la República (AIRA, FDL-1670).

${ }^{119}$ AGNP, PL 14-74, 1834.

${ }^{120}$ Oviedo 1861: 70-71.

${ }^{121}$ AGNA, PL 14-305, 1834; PL, 14-437, 1834. 
su puesto de subprefecto de Huancané, solo pudo recaudar un tercio del tributo, por lo que se le exigieron responsabilidades y se le embargó la hacienda Checayani. ${ }^{122}$

En 1835, sería nombrado sucesivamente subprefecto de Azángaro y de Huancané; y entre 29 de julio y 7 de diciembre de 1835 sería prefecto de Puno. ${ }^{123}$ En todo este periodo, tuvo que afrontar con ciertas dificultades la recaudación de tributos, la actuación de la revisita fiscal y la remisión del contingente impuesto a la provincia. A fines de 1835, descontento del presidente Orbegoso, renunciaría a la prefectura en una coyuntura compleja en la región de Puno. Dicha decisión muestra, según Víctor Peralta, el «desconcierto que tomaba tomar partido por uno u otro contrincante» a raíz del pronunciamiento de Salaverry el 23 de febrero de 1835 y durante la campaña militar de Orbegoso en el sur del país, en la que inicialmente el prefecto Castilla tomó partido por Salaverry, para virar posteriormente y abandonar la región. ${ }^{124}$ En ese contexto, una Junta Departamental puso en la prefectura a Miguel Urbina, entre tanto la región se distanciaría de Orbegoso, apostando por «forzar una federación entre los departamentos del sur». ${ }^{125}$

El ambiente de ese tiempo explica que José Domingo Choquehuanca se sumara a la Confederación Peruano-boliviana, siendo electo en 1837 senador por Puno; y ejerciendo de prefecto de Puno entre 23 de julio y diciembre de 1837; y subprefecto de Huancané en fechas indeterminadas entre 1838 y $1839 .{ }^{126}$ Tras la derrota de la Confederación, fue represaliado por su fidelidad al general Andrés de Santa Cruz, vio expropiadas sus propiedades y optó, sin demasiado éxito, por dedicarse a la explotación

${ }^{122}$ Hünefeldt 1999: 40-41.

${ }^{123}$ Oficios de José Domingo Choquehuanca al secretario general de S. E. el Gran Mariscal Jefe Superior del Ejército Unido, Puno, 5 de agosto, 11 de setiembre y 4 de diciembre de 1835, AIRA, Fondo Denegri Luna-1670).

${ }^{124}$ Peralta 2016: 194.

$125 \mathrm{Ib}$.

${ }^{126}$ José Domingo Choquehuanca al coronel prefecto y comandante general del departamento, 15.3.1838 (AIRA, Fondo Denegri Luna-1670, 1817-1843). Tauro (2001, IV: 650) propone que lo fue entre el 13 de marzo y el 24 de octubre de 1836. 
de la mina Angustias en el distrito puneño de Tiquillaca, ${ }^{127}$ lo que le llevaría a ser diputado de Minería por Puno en $1845 .{ }^{128}$ Entre tanto, mantuvo un largo litigio con su hermana María del Rosario, a quien le recriminaba su proceder, por lo que intentó excluirla del goce la herencia paterna. ${ }^{129}$ En 1846, cuestionaría la testamentaría de su hermana, ${ }^{130}$ dando pie a otro litigio que seguía abierto en 1896, proseguido entonces por su hijo y heredero José Luis Choquehuanca. ${ }^{131}$

Si bien sabemos poco de sus actividades políticas en la década de 1840, consta que intentaría acomodarse de nuevo en la administración estatal. Así, en diciembre de 1842 felicitó por su victoria en Agua Santa al mariscal Domingo Nieto. ${ }^{132}$ Un mes después, en enero de 1843 , le pedía que le encargara alguna revisita de tributos, comprometiéndose a cambio a redactar «una estadística completa según el modelo que publiqué en el año 1833». ${ }^{133}$ Constatamos que su tarjeta de presentación y su aval político seguía siendo su Ensayo de estadistica de Azángaro, y si bien lamentaba que las sucesivas revoluciones hubieran impedido que su modelo se difundiera al conjunto del país, apostillaba que le acreditaba el «no haber dejado de trabajar por el bien de la República... como verá por unos escritos que estoy próximo a publicar». ${ }^{134}$

\section{EL COMPLEMENTO AL RÉJIMEN REPRESENTATIVO}

En 1845, Choquehuanca publicó en el Cusco el Complemento al réjimen representativo mediante el establecimiento de sociedades encargadas de la formación de Proyectos de Ley para acelerar el adelantamiento de la Ilustración, y en su consecuencia la consolidación del Gobierno que hoy rije el Perú.

${ }^{127}$ Frisancho 1953: 12.

${ }^{128}$ Carrasco 1845: 27.

${ }^{129}$ Romero 1936: 41-47. No hemos podido ubicar en la BNP la correspondencia citada.

${ }^{130}$ El testamento de María del Rosario ha sido reproducido en Ramos 2012: 226-231.

${ }^{131}$ Memoria 1896.

132 Un análisis de las bases políticas de este caudillo en McEvoy y Rénique 2010.

${ }^{133}$ José Domingo Choquehuanca al Gran Mariscal D. Domingo Nieto, Mineral de Angustias 20 de diciembre de 1842 y 7 de enero de 1843 (AIRA, Fondo Denegri Luna$1670,1817-1843)$.

${ }^{134} \mathrm{Ib}$. 
En ella, defendía la preeminencia política de ciertos sectores letrados y profesionales, que por su capacidad intelectual y moral podían moldear la legislación vigente. Convencido que la república debía basarse en la tutela de las leyes, proponía la creación de sociedades que promovieran la formulación de proyectos legislativos, de códigos civil, criminal y de procedimientos judiciales, militar y de minería; complementados con reglamentos de hacienda, comercio y policía, de amortización y consolidación de la deuda pública; además de formular planes de enseñanza, civilización de los indígenas, promoción económica y obras públicas. ${ }^{135}$ Partía del presupuesto de que «la moral política depende de las leyes, de la educación y de las costumbres», ${ }^{136}$ y de que la finalidad era trabajar por el bien de la Patria, las virtudes republicanas y la felicidad, que se gozaba por el «dominio del saber y las virtudes». ${ }^{137}$ El objetivo era superar el cuestionamiento constante de la legislación vigente, aprobada a su entender al calor de las pasiones políticas encontradas, y lograr la promulgación de «leyes discutidas por el concurso de las luces de toda la nación; y en consecuencia, sancionadas por la opinión general de la República». ${ }^{138}$

Su discurso político y sociológico, al tiempo que seńalaba la falta de dirigentes intelectuales, definía el perfil de quienes debían serlo. Esbozó un principio de clasificación social basado en varios factores: «el grado de ilustración del Pueblo Peruano», la "moral política [...] adecuada a los principios de un Gobierno Popular representativo» y «la distribución de las riquezas [que] asegura la libertad, e independencia de un ciudadano que se considera libre». ${ }^{139}$ En sus consideraciones, tenía en cuenta el nivel de educación, la actuación política de los dirigentes y/o sujetos pasivos y la pertenencia racial. Percibía la sociedad de mediados del siglo XIX estratificada según el "grado de ilustración del pueblo peruano» ${ }^{140}$ y dividida en cuatro clases, ilustrada, culta, civilizada y semibárbara,

\footnotetext{
${ }^{135}$ Choquehuanca 1845: 40-44.

${ }^{136} \mathrm{Ib} .: 12$.

${ }^{137} \mathrm{Ib} .: 7$.

${ }^{138}$ Ib.: 6-7.

${ }^{139} \mathrm{Ib}$.: 8 .

${ }^{140} \mathrm{Ib}$.
} 
en función de su mayor o menor capacidad de tener conciencia de sí, de ser actores políticos en defensa de la República o de participar adecuadamente en el gobierno popular representativo y de crear y moldear la opinión pública. ${ }^{141}$

La clase ilustrada era la minoritaria, constituida por «ciudadanos eminentes por su inteligencia en aquellas ciencias que influían directamente en la legislación de un gobierno popular representativo" y compuesta por los altos cargos del Parlamento y de la administración del Estado, quienes "con sus escritos han ilustrado la República». ${ }^{142}$ En el terreno político, la clase ilustrada del «pueblo versátil que no siempre los considera en las elecciones para la representación nacional», mostrando «su libertad e independencia individual en el estado político». ${ }^{143}$ Junto con la clase culta, eran las difusoras de la opinión pública entre las otras clases. En concreto, la clase culta, dominada por «un furor democrático» y consciente de la tendencia al absolutismo de todo poder supremo, «ha hecho las transformaciones más extraordinarias en la opinión, contra los gobiernos, y en consecuencia se ha formado el carácter nacional por las instituciones democráticas». ${ }^{144}$

La clase culta dominaba las ciencias útiles a la sociedad y aquellas que no influían en «la legislación de un gobierno popular representativo». ${ }^{145}$ Su mayor logro había sido propagar entre la opinión pública su «fervor democrático». ${ }^{146}$ En general, la clase culta había alcanzado "algunas nociones, sobre política y demás ciencias relativas a la felicidad social», se hallaba "poseída de un furor democrático" y había formado la opinión pública contra gobiernos que tendían al absolutismo. ${ }^{147}$ Choquehuanca insistía en el déficit formativo para el caso de los hombres de leyes, cuya formación se basaba en los derechos romano, español, canónico,

\footnotetext{
${ }^{141}$ Ib.: 11.

142 Ib.: 9.

$143 \mathrm{Ib}$.

${ }^{144}$ Ib.: 11.

${ }^{145}$ Ib.: 9.

146 Ib.: 9-14.

${ }^{147}$ Ib.: 11.
} 
natural y gentes; entre tanto, otras ciencias y profesiones se hallaban en ciernes en el Perú, circunscrita a estudios de medicina y cirugía o teología (escolástica, moral, mística).

Los integrantes de la clase civilizada sabían leer, escribir y contar, habían interiorizado los usos y costumbres de la clase culta, tenían «buenas maneras, urbanidad en su trato, y buen sentido» y conocían «una o más industrias que constituyen la prosperidad de los pueblos». ${ }^{148}$ Se trataba, en palabras del autor, de la clase productora que controlaba la mayor parte de la riqueza del Perú, si bien carecían de la moral política suficiente para la «práctica de las instituciones de un gobierno popular representativo", ${ }^{149}$ compartían una "pasión vehemente por la libertad y la independencia y por las instituciones democráticas» y eran contrarios a todo poder absoluto. ${ }^{150}$

La riqueza de ambas clases, culta y civilizada, había sido mermada por la aguda crisis económica posindependencia, a la que habían contribuido varios supuestos: la caída de las exportaciones a causa del liberalismo comercial imperante y su consecuente destrucción de la industria interna; la debacle de la minería acuciada por la carencia de capitales, de un banco de habilitación y rescate, de azogues e innovaciones técnicas; el desplome de la producción agropecuaria a causa de la despoblación de la sierra; y la caída de las rentas de los propietarios rústicos y urbanos en un contexto de dominio de las manos muertas y las altas cargas de censos sobre todo tipo de fincas. La solución debía venir de políticas públicas proteccionistas y de fomento económico, al mismo tiempo que su diagnóstico enlazaba de forma diáfana crisis económica, falta de respuesta del gobierno y corrupción política, ya que, en sus palabras, los miembros de las asambleas populares, ante el deterioro económico, «venderán su voto a vil precio» y en las Cámaras legislativas los representantes no «obraran con libertad». ${ }^{151}$ Para garantizar el "carácter republicano», se debía asegurar la riqueza de los miembros del legislativo, y con ello

\footnotetext{
${ }^{148} \mathrm{Ib} .: 18$.

${ }^{149} \mathrm{Ib}$.

${ }^{150} \mathrm{Ib} .: 17-18$.

${ }^{151} \mathrm{Ib} .: 15-17$.
} 
evitar que cayeran en actitudes «mercenarias» o que persiguieran solo la búsqueda de su interés particular. ${ }^{152}$ Para el autor, el Perú carecía de moral política por causas que atribuía al egoísmo o a la ignorancia; situación que solo se revertiría si se promovía la educación pública conforme «a las instituciones democráticas». ${ }^{153}$

Su percepción de la clase semibárbara tenía connotaciones de discriminación racial. A su parecer, la integraban indígenas, mestizos rústicos y las «castas procedentes de África marcados por la esclavitud». ${ }^{154}$ Los consideraba seres ignorantes, «sometidos a las leyes» $\mathrm{y}$ «reducidos a sus necesidades meramente naturales, comen y visten groseramente»; ${ }^{155}$ sus actividades económicas se ceñían a «una agricultura sin principio; un comercio sin cálculo; unas fábricas de géneros toscos; y una pastoril ruda». ${ }^{156}$ Se trataba, en fin, de gentes miserables y pobres, sin libertad o independencia en el estado político, que actuaban como «absolutamente pasivos y carentes de cualquier iniciativa propia, que actúan manipulados y al margen de la razón», sin «juicio propio». ${ }^{157}$

Su análisis nos muestra una visión del Perú teñida de fuertes connotaciones excluyentes. Su republicanismo era restrictivo, elitista y al mismo tiempo seguía mostrando tintes regeneracionistas, ya que creía en el desarrollo del país sobre la base de la educación de los grupos inferiores y la promoción de la economía con políticas de carácter proteccionista. El saber era la base de las virtudes republicanas y la moral política, ya que «sin ella el hombre como vemos es un salvaje o bárbaro». ${ }^{158}$. En su propuesta, se acercaba a lo pronunciado por Bartolomé Herrera en las exequias de Agustín Gamarra y en el sermón del 28 de julio de 1846, cuando defendió «la soberanía de la inteligencia», ${ }^{159}$ que, en palabras

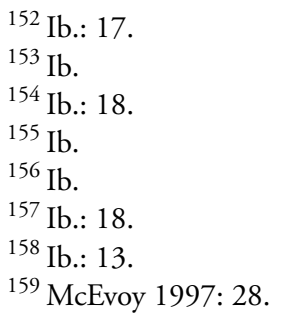


de Carmen McEvoy «señalaba, básicamente, como el derecho a gobernar y dictar leyes debía ser ejercida por aquellos, que la naturaleza hubiera designado como los más capaces», al mismo tiempo que dedicó sus esfuerzos a la educación y a «la formación de una clase dirigente con la capacidad intelectual y moral necesarias para llevar a cabo las complejas tareas gubernativas que el país requería» ${ }^{160}$. Sin embargo, se alejaba de la concepción crítica de Bartolomé de Herrera para con la Confederación Peruana-boliviana y de su defensa del origen divino de la autoridad.

Choquehuanca no circunscribía la educación pública a las escuelas o universidades, sino que consideraba que ella se inculcaría a la población por medio de la creación de escuelas primarias en todos los distritos. En ellas, los peruanos se instruirían en los derechos políticos, a través de la difusión de catecismos políticos, fiestas nacionales, arengas y canciones republicanas en la línea de la Marsellesa. ${ }^{161}$ Para él, era perentoria la reforma de la educación infantil, de los planes de educación superior y la introducción de estudios de economía política y de derecho público constitucional, natural y de gentes, además de los relativos a la legislación civil y penal, siguiendo las propuestas de Jeremy Bentham. ${ }^{162}$ En ello, pudo mostrar la influencia de la prensa regional, que tal y cómo ha apuntado Charles Walker para el Cusco, insertaba y comentaba párrafos de las obras de Bentham, Benjamín Constant o Jean Jacques Rousseau. ${ }^{163}$

Su disertación debe situarse en el contexto de la transición de la cultura jurídica colonial hacia la que se consolidaría en el Perú republicano al promediar el siglo XIX. Se mostraba crítico ante la realidad legislativa imperante y se refería con cierta añoranza a su formación académica charqueña, para denunciar la persistencia de una maraña de leyes y de gran parte de la legislación hispana, sin que se hubiera logrado culminar la codificación de un corpus de leyes que desplegaran los principios constitucionales. Por otro lado, defendía el abandono del derecho romano

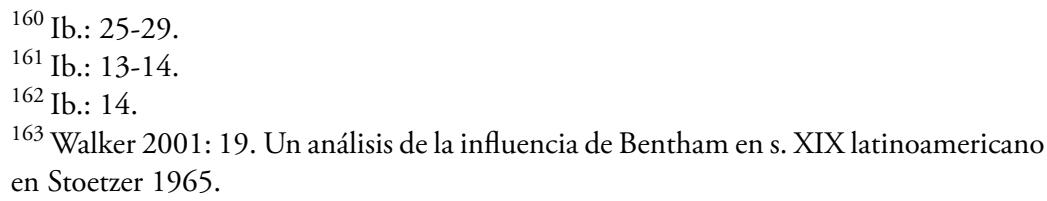


y la maraña de las leyes hispanas aún vigentes, insistía en la necesidad de desarrollar el derecho patrio peruano, por lo que exigía la codificación civil y penal, como muestra de la influencia de Bentham en la cultura jurídica de la época.

La dedicatoria de su obra al presidente Ramón Castilla muestra su fidelidad al caudillo, con quién mantenía relaciones desde su etapa de prefecto de Puno y al que seguiría defendiendo hasta casi el fin de sus días, como apunta su firma estampada en una proclama suscrita por un grupo de puneños el 22 de febrero de 1854 en favor de dicho caudillo en el punto álgido del conflicto con José Rufino Echenique. En 1845, abogaba por un poder fuerte, tutelar para el Perú, y si bien exclamó: "ha aparecido un Wasinton [sic]» ${ }^{164}$ en referencia a Castilla, concluía que el Perú no necesitaba tutela alguna — marcando distancias quizás con la etapa de poder dictatorial bolivariano-, y que el régimen representativo solo se podría consolidar si la clase culta influía a través de las sociedades para "formar una legislación completa cual necesita el Perú». ${ }^{165} \mathrm{Al}$ enfatizar su objetivo, que desbordaba el marco parlamentario, recordaba que «Locke, Newton, Hume, Adam Smith y otros muchos de grande ingenio, no tuvieron asiento en el parlamento británico». ${ }^{166}$

La obra salió de la imprenta al inicio del primer gobierno de Castilla (1845-51) y casi coincidiendo con el establecimiento de una comisión encargada de redactar los códigos civil, penal y de procedimientos judiciales, al amparo de la Ley del 8 de octubre de 1845, cuando era ministro de Justicia José Gregorio Paz Soldán. Sin embargo, no fue hasta 1852 cuando apareció el primer código civil peruano, tras un largo y complejo proceso y un proyecto trunco en $1847 .{ }^{167}$ Jorge Basadre valoró la obra como un texto original de «derecho constitucional aplicado a la realidad»; y al hacer referencia a las organizaciones dirigidas a debatir los problemas nacionales, canalizar la opinión pública y promover una legislación que los resolviera, las comparó con la propuesta de la Sociedad

\footnotetext{
${ }^{164}$ Choquehuanca 1845: 19.

${ }^{165} \mathrm{Ib} .: 21$.

${ }^{166} \mathrm{Ib}$.

${ }^{167}$ Ramos 2001: 167-273.
} 
Patriótica creada en su día por San Martín y Monteagudo, aunque dicha fue concebida con carácter restringido. ${ }^{168}$ Desconocemos el impacto de la obra en el Perú de mediados del siglo XIX; sin embargo, la consideramos producto de un tiempo en el cual se buscaba resolver las tensiones que originaba la coexistencia de ańejos fueros - leyes de Indias, municipales de Castilla - y normas desplegadas en las respectivas constituciones políticas, una amalgama jurídica que condicionaba la superación de las bases y entramado del Antiguo Régimen colonial.

\section{CONCLUSIONES}

En un retrato que se ha conservado, José Domingo Choquehuanca aparece vestido "con la capa y capirote de becario del Colegio de San Antonio Abad, sin ningún elemento que pudiera distinguirlo como representante de la nobleza indígena», ${ }^{169}$ lo cual puede contemplarse como una suerte de metáfora del cambio de estrategias en algunos miembros del linaje de los Choquehuanca entre la Colonia y la República. Nuestro personaje cimentó su carrera pública sobre la base de su formación de abogado en Charcas, su experiencia en la acción política y legislativa en Puno y Lima, su condición de experto en la por entonces novedosa ciencia estadística, para posteriormente defender la necesidad de abordar la codificación en defensa del constitucionalismo republicano y para abolir definitivamente los fueros de raíz colonial.

Durante la Colonia, el linaje de los Choquehuanca basó su preeminencia social y política en dones y privilegios obtenidos en premio a sus servicios prestados a la Corona. Su radio de acción se limitó a la región puneña, de donde no pudieron trascender, y su poder emanaba del control del gobierno étnico. Tras la abolición del cacicazgo y la guerra de la Independencia, solo pudieron mantenerse dentro de la elite regional puneña gracias a su formación en derecho y a su capacidad de incorporarse a las nuevas formas representativas y de alinearse con determinadas

${ }^{168}$ Basadre 1961-1968, II: 895.

${ }^{169}$ Majluf 2005: 285. El retrato, fechado en torno a 1830, se conserva en el Museo Nacional de Arqueología, Antropología e Historia del Perú. 
clientelas políticas que determinaron y condicionaron el ejercicio de la política, además de rentabilizar el manejo de nuevas corrientes de pensamiento que nutrieron las culturas políticas y jurídicas de su tiempo, como fueron las escuelas de la Ilustración napolitana, escocesa, francesa o del utilitarismo anglosajón. La generación de José Domingo Choquehuanca solo pudo mantener su proyección pública adaptándose a las normas que primaban la meritocracia para escoger a los mejores candidatos para cargos administrativos o representativos; si bien en la práctica siguieron siendo fundamentales las relaciones de parentesco y personales o entrar a formar parte de determinadas clientelas políticas, muchas veces basadas en relaciones de patronazgo, en cuya cúspide se instalaron los respectivos caudillos. Sus textos políticos, producidos entre 1825 y 1845, surgieron en una larga coyuntura caracterizada por la fragilidad institucional, la elevada rotación de autoridades y la persistencia de un alto grado de conflictividad regional, factores que le obligaron a constantes reacomodos para seguir manteniendo su presencia pública.

El límite de toda biografía intelectual estriba en que solo sabremos si puede extrapolarse su experiencia a otros casos de las elites puneñas o indígenas cuando contemos con el suficiente número de historias de vida que permitan entrever su originalidad o si su experiencia, pensamiento y propuestas políticas fueron más o menos compartidos. Y es por ello que declino concluir si se trató de una trayectoria singular o si fue compartida por muchos puneños de su generación.

\section{BIBLIOGRAFÍA}

Abecia, Valentín. 1939. Historia de Chuquisaca. Sucre: Edit. Charcas.

Acevedo Medina, A. 1922. Breves apuntes históricos sobre José Domingo Choquehuanca. La Paz: Editorial Cóndor.

Águila, Alicia del. 2012. «Historia del sufragio en el Perú, s. XIX-XX: una lectura desde la ciudadanía y la participación indígena». En Del Águila, Alicia y Milagros Suito (coeds.). Participación electoral indígena y cuota nativa en el Perú. Aportes para el debate. Lima: Jurado Nacional de Elecciones-Institute for Democracy and Electoral Assistance, 17-36.

2013. La ciudadania corporativa: Politica, constituciones y sufragio en el Perú (1821-1896). Lima: Instituto de Estudios Peruanos. 
Alaperrine-Bouyer, Monique. 2007. La educación de las élites indígenas en el Perú colonial. Lima: Instituto Francés de Estudios Andinos, Instituto de Estudios Peruanos e Instituto Riva-Agüero.

Altamirano, Nelson. 1991. «La economía campesina en Puno: 1820-1840. Repercusiones de la presencia militar y la producción textil». Allpanchis. Núm. 37: 93-130.

Altuve, Leonardo. 1991. Choquehuanca y su arenga a Bolivar. Buenos Aires: Planeta.

Ares, Berta. 1999. «Mestizos en hábito de indios: ¿estrategias transgresoras o identidades difusas?». En Berta Ares et al. Passar as fronteiras. Il coloquio internacional sobre mediadores culturais, séculos XV a XVIII. Lagos: Centro de Estudos Gil Eanes: 133-146.

Barinaga, Manuel. 1896. Memoria presentada por el Ministro de Justicia, Culto e Instrucción al Congreso Ordinario. 1896. Lima: Ministerio de Justicia, Culto e Instrucción Pública.

Basadre, Jorge. 1961-1968. Historia de la República del Perú, 1822-1933. Lima: Ediciones Historia, $11 \mathrm{t}$.

Burga, Manuel. 1984. «Elites regionales y autoridades tradicionales». En Altamirano, Germán et al. Mundo andino y región. Lima: Universidad Nacional Mayor de San Marcos, $\mathrm{xx}-\mathrm{xx}$.

Bustamante, Jesús. 2014. «Estadística o censo? La probabilidad como una cuestión política y moral». En Bustamante, Jesús y Giraudo, Laura. La novedad estadística. Cuantificar, cualificar y transformar las poblaciones en Europa y América Latina, siglos XIX y XX. Madrid: Ed. Polifemo, 9-83.

Cabello, Pedro Mariano. 1865. Guía política. Eclesiástica y militar del Perú el año de 1865. Lima: Imprenta de la Guía.

Carrasco, Eduardo. 1840. Calendario y guía de forasteros de la República Peruana para el año 1841. Lima: Imprenta de Instrucción Primaria.

1845. Calendario y guia de forasteros de la República peruana para el año de 1846. Lima: Imprenta de Instrucción Primaria.

Choquehuanca, José Domingo. 1833. Ensayo de estadística completa de los ramos económico políticos de la provincia de Azángaro en el departamento de Puno de la república peruana del quinquenio contado desde 1825 hasta 1829 inclusive. Lima: Imp. de Manuel Corral.

.1845. Complemento al régimen representativo mediante el establecimiento de sociedades encargadas de la formación de proyectos de ley para acelerar los adelantamientos de la ilustración, y en su consecuencia la consolidación del gobierno que hoy rije el Perú. Cusco: Imprenta del Estado por Evaristo González.

Colección de Leyes, decretos y órdenes publicadas en el Perú desde su Independencia en el año 1821 hasta 31 de diciembre de 1830. 1832. Lima: Imp. de José Macías.

Coloma Porcari, César. 1989. «Don Francisco Chuquihuanca Ayulo: ¡el último inca?». Boletín de Lima. Núm. 66: 5-13. 
Cook, Noble David. 1975. Tasa de la visita general de Francisco de Toledo. Lima: Universidad Nacional Mayor de San Marcos.

Córdova y Urrutia, José María. 1839. Estadística histórica, geográfica, industrial y comercial de los pueblos que componen las provincias del Departamento de Lima. Lima: Imprenta de Instrucción Primaria.

Cuentas, Vicente. 1925. La genealogía de la familia Choquehuanca. Puno: El Siglo. Desrosières, Alain. 2004. La politica de los grandes números. Historia de la razón estadistica. Barcelona: Melusina.

Flores, Javier (ed.). 2001. Justo Sahuaraura Inca y sus Recuerdos de la monarquía peruana. Lima: Fundación Telefónica.

Frisancho, Ignacio. 1953. José Domingo Choquehuanca, en su libro Complemento al régimen representativo. Lima: Talleres Gráficos de la Tipografía Peruana.

1975. Choquehuanca y su estadística de Azángaro. Puno: ed. Los Andes.

García Calderón, Francisco. 1860-1862. Diccionario de Legislación peruana. Lima: Imprenta del Estado, 2v.

Garrett, David T. 2008. "In Spite of Her Sex': The Cacica and the Politics of the Pueblo in the Late Colonial Andes». The Americas. Vol. 64, núm. 4: 547-581. https://doi.org/10.1353/tam.2008.0045

. 2009. Sombras del imperio: La nobleza indigena del Cuzco, 1750-1825. Lima: Instituto de Estudios Peruanos.

González González, Enrique. 2017. El poder de las Letras. Por una historia social de las universidades de la América hispana en el periodo colonial. México: Universidad Nacional Autónoma de México.

Gootenberg, Paul. 1995. Población y etnicidad en el Perú republicano (siglo XIX): algunas revisiones. Lima: Instituto de Estudios Peruanos.

Gori, Esteban de. 2010. «La universidad de Charcas: teoría y acción política». Revista de Historia de la Educación Latinoamericana. Núm. 14: 169-190.

. 2016. «Hombres de saber y de acción en tiempos convulsionados: imaginarios y lenguajes sobre el orden político en Charcas. (Desde las reformas borbónicas hasta la Asamblea del Año XIII)». Anuario de Estudios Americanos. Vol. 73, núm. 1: 199-229. https://doi.org/10.3989/aeamer.2016.1.07

Guibovich, Pedro. 1990. «Los libros del curaca de Tacna». Histórica. Vol. 14, núm.1: 69-84.

Guibovich, Pedro y Luis Eduardo Wuffarden. 2008. Sociedad y gobierno episcopal. Las visitas del obispo Manuel de Molinedo y Angulo, (Cuzco, 1674-1687). Lima: Instituto Francés de Estudios Andinos e Instituto Riva-Agüero. https://doi. org/10.4000/books.ifea.380

Hacking, Ian. 1991. La domesticación del azar: La erosión del determinismo y el nacimiento de las ciencias del caos. Barcelona: Gedisa.

Hünefeldt, Christine. 1982. Lucha por la tierra y protesta indigena. Las comunidades indigenas del Perú entre Colonia y República, 1800-1830. Bonn: BAS. 
. 1999. «Reinventing old Power: State, Tribute, and Indians in Puno». Fronteras de la Historia. Núm. 4: 11-53.

Irurozqui, Marta. 2007. «Del Acta de los Doctores al Plan de Gobierno. Las Juntas en la Audiencia de Charcas (1808-1810)». En Chust, Manuel. 1808. La eclosión juntera en el mundo hispano. México: Colmex, 92-226.

. 2016. «La telaraña de los Doctores. Charcas en el Congreso de Tucumán de 1816». Prismas. Revista de Historia Intelectual. Vol. 20, núm. 2: 153-160.

Jacobsen, Nils. 2013. Ilusiones de la transición: el altiplano peruano, 1780-1930. Lima: Banco Central de Reserva e Instituto de Estudios Peruanos.

Larrea y Loredo, José. 1826. Memoria dispuesta para la representación nacional por el señor ministro de estado en el departamento de hacienda D. José de Larrea y Loredo. Lima.

1827. Principios que siguió el ciudadano José de Larrea y Loredo en el Ministerio de Hacienda: y Sección de Negocios Eclesiásticos de que estuvo encargado. Lima: Imp. rep. por J. M. Concha.

Luna, Lizandro. 1946. Choquehuanca, el Amauta. Lima: Imprenta Gráfica Stylo.

Majluf, Natalia. 2005. «De la rebelión al museo: Genealogías y retratos de los incas, 1781-1900». En Cummins, Thomas et al. Los incas, reyes del Perú. Lima: Banco de Crédito, p. 253-319.

Matto de Turner, Clorinda. 1890. Bocetos al lápiz de americanos célebres. Lima: Imprenta Bacigalupi.

Mayer, Leticia. 2014. «Entre el ciudadano y el hombre medio. Leyes estadísticas, mortalidad e higiene en el siglo XIX». En Bustamante, Jesús; Giraudo, Laura y Leticia Mayer. La novedad estadistica. Cuantificar, cualificar y transformar las poblaciones en Europa y América Latina, siglos XIX y XX. Madrid: Ed. Polifemo, 85-126.

McEvoy, Carmen. 1997. La utopía republicana. Ideales y realidades en la formación de la cultura politica peruana (1871-1919). Lima: Pontificia Universidad Católica del Perú.

McEvoy, Carmen y José Luis Rénique (eds.). 2010. Soldados de la República. Guerra, correspondencia y memoria en el Perú (1830-1844). Lima: Fondo Editorial del Congreso del Perú e Instituto Riva-Agüero.

Méndez, Cecilia. 1993. Incas sí, indios no: Apuntes para el estudio del nacionalismo criollo en el Perú. Lima: Instituto de Estudios Peruanos.

Monguió, Luis. 1967. Don José Joaquín Mora y el Perú del ochocientos. Berkeley and Los Angeles: University of California Press.

Morelli, Federica. 2007. «Filangieri y la 'Otra América': historia de una recepción». Revista de la Facultad de derecho y ciencias políticas. Vol. 37, núm. 107: 485-508.

Mostajo, Francisco. 1953. «Los Chuquihuancas hasta la época de Túpac Amaru». Revista de la Universidad de Arequipa. Vol. XXV, núm. 38: 103-4. 
O'Phelan, Scarlett. 1997. Kurakas sin sucesiones: del cacique al alcalde de indios (Perú y Bolivia 1750-1835). Cusco: Centro de Estudios Regionales Andinos Bartolomé de las Casas. 1998. «Kurakas, linajes y el movimiento nacional Inca del siglo XVIII». Actas del IV Congreso Internacional de Etnohistoria. Lima: Pontificia Universidad Católica del Perú, 152-165. Tomo 1. . (comp.). 2017. 1814: La junta de gobierno del Cuzco y el sur andino. Lima: Instituto Francés de Estudios Andinos y Pontificia Universidad Católica del Perú. Ortiz Fernández, Carolina. 2007. «El pensamiento político de Clorinda Matto de Turner». Investigaciones Sociales. Vol. XI, núm. 18: 379-397.

Oviedo, Juan. 1861. Colección de Leyes, Decretos y órdenes publicadas en el Perú desde el año de 1821 hasta 31 de diciembre de 1859. Lima: Felipe Bailly.

Paredes, José Gregorio. 1832. Calendario y Guia de Forasteros de Lima para el año de 1833. Lima: Impr. de J.M. Masías.

Peloso, Vicent y José Ragas. 2001. «Estadística y sociedad en el Perú poscolonial: el desconocido censo de Lima de 1850». Histórica. Vol. XXV, núm. 2: 275-293

Peralta, Víctor. 1996. «Elecciones, constitucionalismo y revolución en el Cusco, 1809-1815». Revista de Indias. Vol. 56, núm. 206: 99-131.

. 2016. «De prefectos a mandatarios de la Nación. La violencia en la política peruana (1829-1836)». Revista de Indias. Vol. LXXVI, núm. 266: 173-200. https://doi.org/10.3989/revindias.2016.006

Piel, Jean. 1972. Capitalisme agraire au Perou. París: Ed. Anthropos.

Portillo, José María. 2009. La vida atlántica de Victorián Villava. Madrid: Fundación Mapfre-Doce Calles.

Puertas, Néstor. 1948. José Domingo Choquehuanca. Lima: s.i. . 1953. «La investigación histórica acerca de Choquehuanca». Perú indígena. Núm. 12: 76-99.

. 1963. «La personalidad de José Domingo Choquehuanca y su estirpe incarial». Revista de Historia de América. Núm. 55/56: 158-177.

Ragas, José. 2008. «Ideólogos del Leviatán. Estadística y sociedad en el Perú (1791-1876)». En Aguirre, Carlos y Mc Evoy, Carmen (eds.), Intelectuales y poder: Ensayos en torno a la república de las letras en el Perú e Hispanoamérica (ss. XVI-XX). Lima: Instituto Francés de Estudios Andinos e Instituto Riva-Agüero, 151-172

.2013. Obsessed with numbers: Statistics, State Building and the 'Monopoly of Information' in Lima, Perú (1850-1860s)». Paper 127th Annual Conference of The American Historical Association, New Orleans.

Raimondi, Antonio.1876-1879. El Perú. III. Historia de la geografía del Perú. Lima: Lib. e imp. Gil. 
Ramos, Carlos. 2001. Historia del derecho civil peruano, Siglos XIX y XX. II. La codificación del siglo XIX: Los códigos de la Confederación y el Código Civil de 1852. Lima: Fondo Editorial PUCP, 167-273.

Ramos Zambrano, Augusto. 2006. «Los Choquehuanca de Azángaro en el proceso de la Independencia nacional». En Zubieta, Filomeno et al. Pueblos, provinciasy regiones en la historia del Perú. Lima: Academia Nacional de la Historia, 617-639. . 2012. J.D., Choquehuanca: El cantor de Bolivar. Los caciques Chukiwanka y sus testamentos. Lima: Ediciones del autor.

Ramos, Gabriela y Yana Yanakakis (eds.). 2014. Indigenous Intellectuals: Knowledge, Power, and Colonial Culture in Mexico and the Andes. Durham: Duke University Press.

Ratto-Ciarlo, José. 1980. Choquehuanca y la contrarrevolución. Caracas: Comité Ejecutivo del Bicentenario de Simón Bolívar.

Rénique, José Luis. 2004. La batalla por Puno: conflicto agrario y nación en los Andes peruanos, 1866-1995 Lima: Instituto de Estudios Peruanos, Sur y Casa de Estudios del Socialismo.

Ricketts, Mónica. 2013. «De la palabra a la acción: Oradores, editores, abogados y conspiradores en el virreinato del Perú, 1780-1808». Revista de Indias. Vol. 73, núm. 258: 399-430. https://doi.org/10.3989/revindias.2013.013

. 2017. Who Should Rule? Men of Arms, the Republic of Letters, and the Fall of the Spanish Army. New York: Oxford University Press.

Rodríguez Casado, Vicente y Florentino Pérez Embid (eds.). 1947. Memoria de gobierno Manuel de Amat y Junient, virrey del Perú, 1761-1776. Sevilla: Escuela de Estudios Hispanoamericanos.

Romero, Emilio. 1936. «El autor de la famosa arenga a Bolívar». Revista del Instituto Sanmartiniano del Perú. Núm. 3: 41-47.

Rosas, Claudia. 2009. «Entre la satanización y la idealización. La figura del curaca en la historiografía andina contemporánea». Histoire(s) de l'Amérique Latine. Vol. 3.

Sala i Vila, Núria. 1990. «De inca a indígena: Cambio en la simbología del Sol a principios del siglo XIX». Allpanchis. Vol. 35-36, núm. 2: 599-633.

. 1992a. «La constitución de Cádiz y su impacto en el gobierno de las comunidades indígenas en el virreinato del Perú». Boletín americanista. Núm. 33: 51-70.

. 1992b. «La participación indígena en la rebelión de los Angulo y Pumacahua, 1814-16». En García Jordán, Pilar y Miguel Izard, (coords.). Conquista y resistencia en la Historia de América. Barcelona: Universitat de Barcelona, 273-278.

1996. Y se armó el tole-tole! Tributo indígena y movimientos sociales en el Perú. Ayacucho: Instituto de Estudios Regionales José María Arguedas. 
. 2011. «El Trienio Liberal en el Virreinato peruano: los ayuntamientos constitucionales de Arequipa, Cusco y Huamanga, 1820-1824». Revista de Indias. Vol. 71, núm. 253: 693-728. https://doi.org/10.3989/revindias.2011.023 .2012. "Justicia conciliatoria durante el liberalismo hispano en el Perú: el caso de Huamanga». Anuario de Estudios Americanos. Vol. 69, núm. 2: 423-450. https://doi.org/10.3989/aeamer.2012.2.02

. 2014. «La abolición de las intermediaciones étnicas en el gobierno liberal del Cuzco (1820-1824)». Ponencia presentada al Congreso Internacional La independencia antes de las independencias, Lima (en prensa).

. 2016a. «Derecho, poder y libertad» a propósito de las batallas por la autonomía jurisdiccional entre las Audiencias del Cusco y Charcas (1820-1825)». Revista de Indias. Vol. LXXVI, núm. 266: 51-82. https://doi.org/10.3989/ revindias.2016.002

.2016b. «Saberes, ciencias y política en la formación del Estado en el Perú». En Grompone, Romeo (ed.). Incertidumbre y distancias. El controvertido protagonismo del Estado en el Perú. Lima: Instituto de Estudios Peruanos, 147-171. Salazar y Muñatones, Andrés. 2001. Estadistica y contribuciones en el Perú, s. XIX. Lima: Seminario de Historia Rural Andina.

Serulnikov, Sergio. 2013. «El gobierno de los pueblos andinos en el siglo XVIII. Cambios y continuidades». En Campagno, Marcelo; Gallego, Julián y Carlos García (coords.). Rapports de subordination personnelle et pouvoir politique dans la Méditerranée antique et au-delà. Besançon: PUFC, 179-193.

Soux, María Luisa. 2011. «Rebelión, guerrilla y tributo: los indios en Charcas durante el proceso de Independencia». Anuario de Estudios Americanos. Vol. 68, núm. 2: 455-482. https://doi.org/10.3989/aeamer.2011.v68.i2.546

Stoetzer, Otto Carlos. 1965. «El influjo del utilitarismo inglés en la América española». Revista de estudios politicos. Núm. 143: 165-192.

Tauro, Alberto. 2001. Enciclopedia ilustrada del Perú. Lima: Peisa, 5t.

Thibaud, Clément. 2010. La Academia Carolina y la independencia de América. Los abogados de Chuquisaca (1776-1809). Sucre: Editorial Charcas Fundación.

Unánue, Hipólito. 1813. «Compendio Estadístico del Virreinato del Perú a fines del siglo XVIII». El Verdadero Peruano. Núms. XIX, XX y XXII.

Walker, Charles. 2001. «La orgía periodística’: prensa y cultura política en el Cuzco durante la joven república». Revista de Indias. Vol. 61, núm. 221: 7-26.

Wasserman, Fabio. 2011. Juan José Castelli. De súbdito de la corona a líder revolucionario. Buenos Aires: Edhasa.

Fecha de recepción: 21/VII/2017

Fecha de aceptación: 24/IX/2018 